\title{
Agonist Binding to Chemosensory Receptors: A Systematic Bioinformatics Analysis
}

\begin{abstract}
Fabrizio Fierro ${ }^{1 \dagger}$, Eda Suku ${ }^{2 \dagger}$, Mercedes Alfonso-Prieto ${ }^{1,3 *}$, Alejandro Giorgetti ${ }^{1,2 *}$, Sven Cichon ${ }^{4,5,6}$ and Paolo Carloni ${ }^{1,7,8}$

${ }^{1}$ Computational Biomedicine, Institute for Advanced Simulation IAS-5 and Institute of Neuroscience and Medicine INM-9, Forschungszentrum Jülich, Jülich, Germany, ${ }^{2}$ Department of Biotechnology, University of Verona, Verona, Italy, ${ }^{3}$ Cécile and Oskar Vogt Institute for Brain Research, Medical Faculty, Heinrich Heine University Düsseldorf, Düsseldorf, Germany, ${ }^{4}$ Institute of Neuroscience and Medicine INM-1, Forschungszentrum Jülich, Jülich, Germany, ${ }^{5}$ Institute for Human Genetics, Department of Genomics, Life\&Brain Center, University of Bonn, Bonn, Germany, ${ }^{6}$ Division of Medical Genetics, Department of Biomedicine, University of Basel, Basel, Switzerland, ' Department of Physics, Rheinisch-Westfälische Technische Hochschule Aachen, Aachen, Germany, ${ }^{8}$ VNU Key Laboratory "Multiscale Simulation of Complex Systems", VNU University of Science, Vietnam National University, Hanoi, Vietnam
\end{abstract}

\section{OPEN ACCESS}

Edited by:

Piero Andrea Temussi,

University of Naples Federico II, Italy

Reviewed by:

Alfonso De Simone,

Imperial College London,

United Kingdom

Christopher Cooper,

University of Huddersfield,

United Kingdom

*Correspondence:

Mercedes Alfonso-Prieto

m.alfonso-prieto@zz-juelich.de

Alejandro Giorgett

a.giorgetti@fz-juelich.de

${ }^{\dagger}$ These authors have contributed equally to this work.

Specialty section:

This article was submitted to

Structural Biology,

a section of the journal

Frontiers in Molecular Biosciences

Received: 22 June 2017

Accepted: 22 August 2017

Published: 06 September 2017

Citation:

Fierro F, Suku E, Alfonso-Prieto M, Giorgetti A, Cichon S and Carloni P (2017) Agonist Binding to

Chemosensory Receptors: A Systematic Bioinformatics Analysis.

Front. Mol. Biosci. 4:63.

doi: 10.3389/fmolb.2017.00063
Human G-protein coupled receptors (hGPCRs) constitute a large and highly pharmaceutically relevant membrane receptor superfamily. About half of the hGPCRs' family members are chemosensory receptors, involved in bitter taste and olfaction, along with a variety of other physiological processes. Hence these receptors constitute promising targets for pharmaceutical intervention. Molecular modeling has been so far the most important tool to get insights on agonist binding and receptor activation. Here we investigate both aspects by bioinformatics-based predictions across all bitter taste and odorant receptors for which site-directed mutagenesis data are available. First, we observe that state-of-the-art homology modeling combined with previously used docking procedures turned out to reproduce only a limited fraction of ligand/receptor interactions inferred by experiments. This is most probably caused by the low sequence identity with available structural templates, which limits the accuracy of the protein model and in particular of the side-chains' orientations. Methods which transcend the limited sampling of the conformational space of docking may improve the predictions. As an example corroborating this, we review here multi-scale simulations from our lab and show that, for the three complexes studied so far, they significantly enhance the predictive power of the computational approach. Second, our bioinformatics analysis provides support to previous claims that several residues, including those at positions 1.50, 2.50, and 7.52, are involved in receptor activation.

Keywords: G-protein coupled receptor, chemosensory receptor, bitter taste receptor, odorant receptor, bioinformatics, homology modeling, molecular docking, molecular mechanics/coarse grained simulations

\section{INTRODUCTION}

The G-protein coupled receptor (GPCR) superfamily is the largest group of plasma eukaryotic membrane receptors, with about 850 members in the human genome (Fredriksson et al., 2003; Lagerstrom and Schioth, 2008; Tikhonova and Fourmy, 2010). According to the GRAFS classification (Schioth and Fredriksson, 2005), human G-protein coupled receptors (hGPCRs) are divided in five different families, i.e., Rhodopsin-like (or class A), Glutamate (or class C), Adhesion 
(or class B2), Frizzled (or class F) and Secretin (or class B1). They all share a seven transmembrane (TM) helix bundle shape (Kobilka, 2007; Venkatakrishnan et al., 2013, 2016; Latorraca et al., 2017). Binding of an extracellular agonist (or a photon in the case of rhodopsin) triggers conformational changes in the receptor. This activates intracellular signaling cascades, leading to downstream events. Because of their crucial role for many cellular signaling pathways, hGPCRs are of immense importance in pharmacology, being the target of $\sim 50 \%$ of currently FDA approved drugs (Schlyer and Horuk, 2006; Lundstrom, 2009; Salon et al., 2011; Tautermann, 2014; Miao and McCammon, 2016).

Approximately half of the members of the hGPCR superfamily are chemosensory receptors (hChem-GPCRs hereafter) (Takeda et al., 2002). These include odorant receptors (hORs), bitter taste receptors (hTAS2Rs) and sweet and umami taste receptors (Buck and Axel, 1991; Chandrashekar et al., 2006; Yarmolinsky et al., 2009). Here we focus on hORs and hTAS2Rs, because they represent the first and third largest hGPCR subfamilies (with $\sim 400$ and $\sim 25$ members, respectively) (Lagerstrom and Schioth, 2008; Foster et al., 2014). Although initially found to be responsible for odorant (Buck and Axel, 1991; Zhao et al., 1998; Firestein, 2001, 2005) and bitter taste perception (Adler et al., 2000; Chandrashekar et al., 2000; Matsunami et al., 2000), it is now recognized that hChem-GPCRs participate in other extranasal (Ansoleaga et al., 2013; Foster et al., 2014; Abaffy, 2015; Ferrer et al., 2016), and extra-oral (Behrens and Meyerhof, 2011; Shaik et al., 2016; Lu et al., 2017) physiological processes. In addition, hChem-GPCRs are involved in pathological processes (Behrens and Meyerhof, 2011; Ansoleaga et al., 2013; Foster et al., 2014; Abaffy, 2015; Ferrer et al., 2016; Shaik et al., 2016; Lu et al., 2017). Thus, they are emerging as promising targets for pharmaceutical intervention (Foster et al., 2014; Ferrer et al., 2016; Shaik et al., 2016; Lu et al., 2017), as it happened in the past for other GPCRs (Schlyer and Horuk, 2006; Lundstrom, 2009; Salon et al., 2011; Tautermann, 2014; Miao and McCammon, 2016).

hORs belong to class A GPCRs, sharing with the other class A GPCRs several conserved motifs (de March et al., 2015a) (see Table 1). They are expressed in different tissues, from the cilia of olfactory sensory neurons in the nose, to the testis, the gut, the skin, the tongue, leucocytes, thrombocytes, the skeletal muscle, primordial germ cells and oocytes, the atrioventricular node and the brain (Goto et al., 2001; Spehr et al., 2003; Durzynski et al., 2005; Feldmesser et al., 2006; Braun et al., 2007; Jenkins et al., 2009; Breer et al., 2012; Ansoleaga et al., 2013, 2015; Flegel et al., 2013, 2015; Garcia-Esparcia et al., 2013; Wijten et al., 2013; Busse et al., 2014; Grison et al., 2014; Malki et al., 2015; Ko and Park, 2016). Their functions span from olfaction to sperm chemotaxis, to regulation of renal function, to regeneration and migration in muscle cells, or to neuronal regulation (Spehr et al., 2004; Griffin et al., 2009; Pluznick et al., 2009; Grison et al., 2014; Ferrer et al., 2016). hORs are connected to several diseases, including cervical cancer, prostate cancer, pancreatic ductal adenocarcinoma, CreutzfeldtJakob's disease, Alzheimer's disease, progressive supranuclear palsy, schizophrenia, and retinitis pigmentosa (Wang et al., 2006;
TABLE 1 | Shared conserved motifs between Class A GPCRs (Lagerstrom and Schioth, 2008; Venkatakrishnan et al., 2013; Tehan et al., 2014), hTAS2Rs (Pydi et al., 2014a, 2016; Di Pizio et al., 2016), and hORs (de March et al., 2015a).

\begin{tabular}{|c|c|c|c|}
\hline $\begin{array}{l}\text { TM } \\
\text { helix }\end{array}$ & Class A & hTAS2Rs & hORs \\
\hline TM1 & $N^{1.50} x x V^{1.53}$ & $N^{1.50} x \times I^{1.53}$ & $G^{1.49} N^{1.50} x \times 1^{1.53}$ \\
\hline $\mathrm{TM} 2$ & $L^{2.46} x x x D^{2.50}$ & $L^{2.46} \times x \times R^{2.50}$ & $L^{2.46} S^{2.47} \times x D^{2.50}$ \\
\hline TM3 & $D[E]^{3.49} R^{3.50} Y^{3.51}$ & $L^{3.46} x x F^{3.49} Y^{3.50} x x K^{3.53}$ & $D[E]^{3.49} R^{3.50} Y^{3.51}$ \\
\hline TM4 & $W^{4.50}$ & 4.50 not conserved & $W^{4.50}$ \\
\hline TM5 & $\begin{array}{l}- \\
P^{5.50} \\
-\end{array}$ & $\begin{array}{l}L^{5.39} \times x S^{5.42} L^{5.43} \\
P^{5.50}\end{array}$ & $\begin{array}{l}- \\
5.50 \text { is not conserved } \\
S^{5.57} Y^{5.58}\end{array}$ \\
\hline TM6 & $\begin{array}{l}{ }^{6.44} x x \times W^{6.48} x \\
P^{6.50}\end{array}$ & $\begin{array}{l}F^{6.44} x x x Y^{6.48} \\
6.50 \text { is not conserved }\end{array}$ & $\begin{array}{l}\text { KAFSTCXSH } \\
- \\
6.50 \text { is not conserved }\end{array}$ \\
\hline TM7 & $N^{7.49} P^{7.50} x x Y^{7.53}$ & $\left.\mathrm{H}^{7.49} \mathrm{~S}^{7.50} \times \mathrm{II}\right]^{7.52} \mathrm{~L}^{7.53}$ & $N^{7.49} P^{7.50} \times I[L]^{7.52} Y^{7.53}$ \\
\hline
\end{tabular}

Residue positions are indicated using the Ballesteros-Weinstein numbering (Ballesteros and Weinstein, 1995).

Neuhaus et al., 2009; Kang and Koo, 2012; Zhou et al., 2012; Ansoleaga et al., 2013; Rodriguez et al., 2014; Ma et al., 2015; Guerrero-Flores et al., 2017).

hTAS2Rs have been suggested either to form a distinct, novel GPCR class, or to belong to class F (Fredriksson et al., 2003), or class A (Nordstrom et al., 2011; Cvicek et al., 2016). The latter hypothesis has been recently corroborated by phylogenetic analyses (Nordstrom et al., 2011), as well as by the observation that several class A motifs are also conserved in hTAS2Rs (Di Pizio et al., 2016; Table 1). hTAS2Rs are located in the tongue and palate epithelium, but also in the gastrointestinal tract, heart, leukocytes, vascular smooth muscle cells, bone marrow derived mesenchymal cells and sinonasal cells of the airway epithelium, and the brain (Hoon et al., 1999; Meyerhof, 2005; Sternini, 2007; Behrens and Meyerhof, 2009; Singh et al., 2011b; Garcia-Esparcia et al., 2013; Lund et al., 2013; Foster et al., 2014; Lee and Cohen, 2014; Manson et al., 2014; Ansoleaga et al., 2015; Malki et al., 2015; Shaik et al., 2016). hTAS2Rs' extra-oral roles include detection of toxins, bronchodilation, and hormone secretion (Janssen et al., 2011; Lee et al., 2012; Robinett et al., 2014). Moreover, polymorphic variants of hTAS2Rs have been found to be correlated to diseases, such as chronic rhinosinusitis and cystic fibrosis, pancreatic cancer, risk of dental caries and vection-induced motion sickness and nausea (Wendell et al., 2010; Benson et al., 2012; Adappa et al., 2014; Gaida et al., 2016; Shaik et al., 2016; Lu et al., 2017).

Cheminformatics methods have provided encouraging results regarding the in silico prediction of sensory attributes of chemicals (bitterness or smell) using either machine-learning algorithms, or ligand-based methods, or (binding site) structurebased methods (Bahia et al., 2017; Keller et al., 2017). However, an important limitation is represented by the paucity of the experimental data and by the reliability of the psychophysical tests that these methods often use (Bahia et al., 2017; Keller et al., 2017). Furthermore, it is still not possible to predict the smell quality of a compound from its chemical structure or whether a given molecule has a perceived odor (Keller et al., 2017). 
Understanding agonist binding of hChem-GPCRs at the molecular level can provide complementary insights on chemical sensing (Charlier et al., 2013; Di Pizio and Niv, 2014; Suku et al., 2017), as well as offer exciting and unexplored opportunities for drug design (Foster et al., 2014; Ferrer et al., 2016; Shaik et al., 2016; Lu et al., 2017). In addition, it may provide hints on receptors' agonist binding site architecture (Sandal et al., 2015) and activation mechanisms (Lai et al., 2005, 2014; Biarnes et al., 2010; Dai et al., 2011; Singh et al., 2011a; Pydi et al., 2014a; de March et al., 2015b). Because of the lack of experimental structural information, structural insights rely on computations (reviewed in Charlier et al., 2013; Di Pizio and Niv, 2014; Suku et al., 2017). The predictions may be validated against site-directed mutagenesis and functional (agonist dose-response curves) assays (Table 2). By measuring changes in the half maximal effective concentration $\left(\mathrm{EC}_{50}\right)$ values of the ligand upon specific mutations (see Supplementary Table 1 ), one can pinpoint residues important for ligand binding and/or activation. Nonetheless, the $\mathrm{EC}_{50}$ values are measured using downstream signaling effects (e.g., cAMP, $\mathrm{Ca}^{2+}$ ions or $\mathrm{IP}_{3}$ concentration increase Restrepo et al., 1990; Bruch, 1996; Berridge et al., 2000; Clapp et al., 2001; Matthews and Reisert, 2003), and thus one cannot disentangled whether the observed changes are associated only with ligand binding and/or with the resulting signal transduction cascade caused by receptor activation (Colquhoun, 1998; Strange, 2008, 2010; Williams and Hill, 2009) (see Supplementary Information Section 2.1 for further details).
Hence, validation of the predictions may be in principle carried out (i) by cross-checking whether the residues whose mutations are associated with $\mathrm{EC}_{50}$ changes are forming actual interactions with the ligand in the model and/or have an impact on activation and (ii) by predicting new residues involved in binding or activation that are subsequently verified experimentally. In practice, the former mutations are much easier to design than the latter.

Computational approaches aimed at structural predictions of hChem-GPCR/ligand complexes (reviewed in Charlier et al., 2013; Di Pizio and Niv, 2014; Suku et al., 2017) include homology modeling, based on GPCR X-ray structures as templates, along with molecular docking, often guided by information about the putative binding site, as done for other GPCRs (Michino et al., 2009; Kufareva et al., 2011, 2014). Unfortunately, on one hand the sequence identity of hChem-GPCRs with GPCRs for which experimental structural information is available, is $<20 \%$ (Charlier et al., 2013; Di Pizio and Niv, 2014; Suku et al., 2017). Hence, the resulting homology models have low statistical confidence. In particular, the orientation of the side chains, essential for protein-ligand interactions, is not accurately predicted (Chothia and Lesk, 1986; Baker and Sali, 2001; Eramian et al., 2008; Piccoli et al., 2013; Busato and Giorgetti, 2016). On the other hand, standard docking algorithms, while very successful to predict ligand poses when high resolution experimental structures are used (Michino et al., 2009; Katritch et al., 2010; Kufareva et al., 2011, 2014; Beuming and Sherman, 2012), may also show limited predictive power in the case

TABLE 2 | Human chemosensory GPCRs (hChem-GPCRs)/agonist complexes for which experimental data are available.

\begin{tabular}{|c|c|c|c|}
\hline hChem-GPCR & Agonist (charge) & Complex abbreviation & Reference \\
\hline hTAS2R1 & dextromethorphan (+1) & $\mathrm{T} 2 \mathrm{R} 1 / \mathrm{dmx}$ & Singh et al., 2011a \\
\hline hTAS2R4 & quinine $(+1)$ & T2R4/quin & Pydi et al., 2014b,c \\
\hline \multirow[t]{3}{*}{ hTASR10 } & denatonium $(+1)$ & T2R10/dena & Born et al., 2013 \\
\hline & parthenolide (0) & T2R10/parthe & \\
\hline & strychnine $(+1)$ & T2R10/strych & \\
\hline hTAS2R16 & salicin (0) & T2R16/sali & \\
\hline hTAS2R30 & denatonium $(+1)$ & T2R30/dena & Pronin et al., 2004 \\
\hline hTAS2R31 & aristolochic acid $(-1)$ & T2R31/aristo & Pronin et al., 2004; Brockhoff et al., 2010 \\
\hline \multirow[t]{2}{*}{ hTAS2R38 } & phenylthiocarbamide (0) & T2R38/PTC & Biarnes et al., 2010; Marchiori et al., 2013 \\
\hline & propylthiouracil (0) & T2R38/PROP & \\
\hline \multirow[t]{3}{*}{ hOR1A1 } & $(R)-(-)$-carvone $(0)$ & OR1A1/R-carvone & Geithe et al., 2017 \\
\hline & (S)-(+)-carvone (0) & OR1A1/S-carvone & \\
\hline & citronellol (0) & OR1A1/citro & Schmiedeberg et al., 2007 \\
\hline hOR2AG1 & amylbutyrate (0) & OR2AG1/amyl & Gelis et al., 2012 \\
\hline hOR2M3 & 3-mercapto-2-methyl-pentan-1-ol (0) & OR2M3/3-mercapto & Noe et al., 2016 \\
\hline \multirow[t]{2}{*}{ hOR7D4 } & androstadienone (0) & OR7D4/androste & Keller et al., 2007; Zhuang et al., 2009 \\
\hline & androstenone (0) & OR7D4/androsta & \\
\hline
\end{tabular}


of hChem-GPCRs (Stary et al., 2007; Biarnes et al., 2010; Launay et al., 2012; Marchiori et al., 2013; Sandal et al., 2015) (see Supplementary Information Section 1.1). These methods usually cannot take fully into account receptor dynamics and hydration (Katritch et al., 2010; Spyrakis et al., 2011; Spyrakis and Cavasotto, 2015), crucial for ligand binding and receptor activation in GPCRs (Pardo et al., 2007; Angel et al., 2009; Nygaard et al., 2010; Latorraca et al., 2017).

Refinement of the hChem-GPCR/ligand complex models have been carried out by molecular dynamics (MD) simulation (Gelis et al., 2012; Lai and Crasto, 2012; Charlier et al., 2013; Marchiori et al., 2013; Lai et al., 2014; Sandal et al., 2015). This approach may alleviate some of the limitations of the bioinformatics procedure (Charlier et al., 2013; Di Pizio and Niv, 2014; Suku et al., 2017). In particular, it allows a more extensive exploration of the conformational space in the presence of the solvent (Spyrakis et al., 2011; Chen, 2015; Spyrakis and Cavasotto, 2015; Broomhead and Soliman, 2017), though at the expense of a higher computational cost.

Here, we investigate for the first time the reliability of bioinformatics/docking predictions, by systematically predicting the structural determinants of ligand binding in hChem-GPCRs for which experimental mutagenesis data are available (Table 2 and Supplementary Table 1). We focus on mutants located in the top half of the receptor, because this is the location of the canonical orthosteric binding site of class A GPCRs, as known from the available crystal structures of ligand/receptor complexes (Venkatakrishnan et al., 2013). We use a stateof-the art homology modeling protocol together with blind molecular docking-based tools used previously for hChemGPCRs' structural predictions (reviewed in Di Pizio and Niv, 2014). It turns out that only $36 \%$ or less of the predictions are consistent with experiment (under the assumption that all of the mutants considered are involved, at least in part, directly or indirectly, in ligand binding). The predictive power varies from system to system in a non-trivial manner. Hence, while bioinformatics/docking-based models constitute an excellent starting point to study ligand binding, they may require structural refinement to improve their agreement with experiment, as well as to increase their predictive power. We show that this is the case for the three systems investigated so far with our multiscale MD simulation approach (Marchiori et al., 2013; Sandal et al., 2015).

We close this investigation by analyzing the experimentally characterized residues that have been suggested to be involved in activation in hChem-GPCRs (Biarnes et al., 2010; Singh et al., 2011a; Pydi et al., 2012, 2014a). These are residues whose mutation causes changes in receptor's response, from abolishing activation to constitutive activation. Using bioinformatics analyses, we provide interesting information regarding a novel conserved hydrophobic position that may be involved in activation of hTAS2Rs, but also hORs and, in general, class A GPCRs. These analyses, together with the phylogenetic tree in reference (Nordstrom et al., 2011) and the conservation of some TM motifs (Table 1; Di Pizio et al., 2016), support the classification of hTAS2Rs as a branch diverging from class A GPCRs.

\section{RESULTS AND DISCUSSION}

Here we present first an assessment of the quality of models of hChem-GPCRs based on bioinformatics and molecular docking. Next, we show that bioinformatics approaches also corroborate previous suggestions on the role of specific residues of hTAS2Rs for activation.

\section{Bioinformatics-Based Binding Predictions}

Multiple sequence alignments (MSAs) of hTAS2Rs and hORs (see Section 1.2 of the Supplementary Information) were considered for the creation of the Hidden Markov Model (HMM) profiles of both subfamilies. These profiles were then used for template search among the GPCRs with known structure using the GOMoDo pipeline (Sandal et al., 2013). The templates turned out to share a sequence identity of $11-20 \%$ with the targets. The best template corresponds to the human class A GPCR $\beta 2$ adrenoceptor (PDB code: 4LDE, X-ray resolution: $2.79 \AA$ Ring et al., 2013). Indeed, this template is one of the top ranked templates based on the HHsearch output (Soding et al., 2005), in which all the conserved features of the target-template alignment are captured (see Section 1.3 of the Supplementary Information). In addition, the models generated with this template present consistently the best MODELLER quality scores (Melo et al., 2002; Shen and Sali, 2006) for all hChem-GPCRs. Finally, the template is in a fully activated state (Venkatakrishnan et al., 2016), which is expected to be the agonist-bound conformational state; this is particularly important here because all the ligands in Table 2 are agonists. Hence, this template was used to generate all the hChem-GPCR models, ensuring uniformity of the predictions.

Homology models were built following a protocol previously used in references (Marchiori et al., 2013; Sandal et al., 2013, 2015). Agonists' binding modes were predicted using blind docking approaches and programs previously used for hChemGPCRs (Stary et al., 2007; Launay et al., 2012; Marchiori et al., 2013; Sandal et al., 2015). These include: HADDOCK (Dominguez et al., 2003), AutoDock Vina (Trott and Olson, 2010), and Glide (Friesner et al., 2004).

To characterize the quality of the binding poses (Supplementary Figures 2-4), precision (PREC) and recall (REC) values are calculated for each of the hChem-GPCR/agonist complex predictions and for each of the docking programs (Figure 1 and Table 3). We find that the bioinformatics results vary from system to system in a non-trivial manner. For instance, the predictions for the same receptor with three different agonists (e.g., hTAS2R10 in complex with denatonium, parthenolide or strychnine) have significantly different values of recall and precision. This is also the case when comparing the docking of the same agonist to two different receptors (such as strychnine bound to hTAS2R10 and hTAS2R46).

The three docking programs used in this study [HADDOCK (Dominguez et al., 2003), AutoDock Vina (Trott and Olson, 2010) and Glide (Friesner et al., 2004)] give similar predictions for some of the complexes analyzed. The predictions for hOR7D4 in complex with androstenone and androstadienone show high precision for all three docking programs, but low 
A

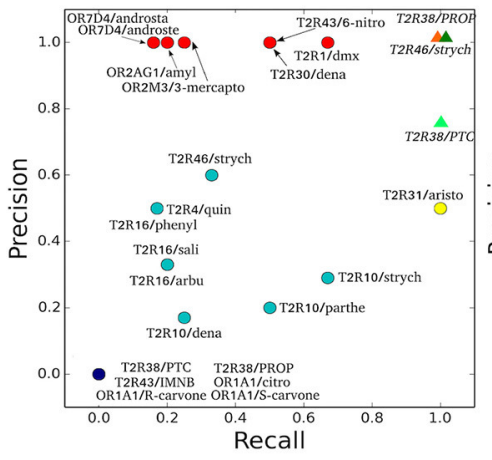

B

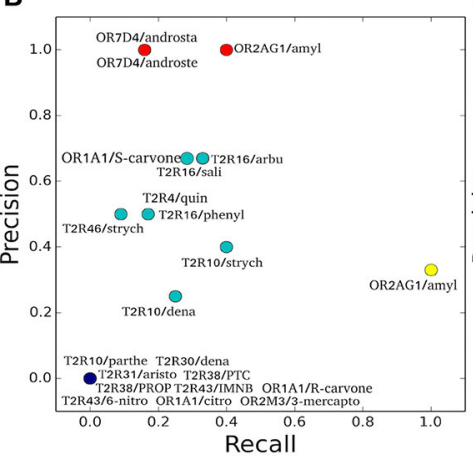

c

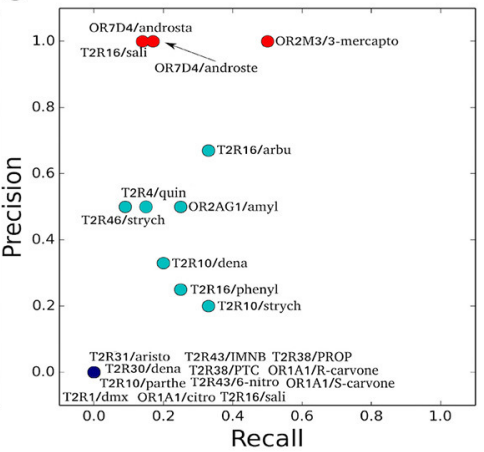

FIGURE 1 | Precision and Recall plots for the predictions of hChem-GPCR/agonist complexes. (A-C) show the HADDOCK (Dominguez et al., 2003), AutoDock Vina (Trott and Olson, 2010), and Glide (Friesner et al., 2004) docking predictions, respectively. The abbreviations used for the hChem-GPCR/agonist complexes are listed in Table 2. Bioinformatics/Docking-based predictions are shown as circles, colored according to the two performance metrics: dark blue (0 precision, 0 recall), red (precision 1, low recall), yellow (low precision, recall 1) and cyan (all the rest, with intermediate precision and recall values). In panel A, MM/CG simulation results (Marchiori et al., 2013; Sandal et al., 2015), started from Haddock docking complexes, are displayed as colored triangles.

recall (Figure 1, red circles). In contrast, the predictions for the hTAS2R38/PROP and PTC complexes, as well as the hTAS2R43/IMNB, hOR1A1/citronellol and hOR1A1/(R)-(-)carvone complexes, show all recall and precision equal to zero (Figure 1, dark blue circles). Finally, the predictions for hTAS2R10 in complex with denatonium and strychnine, as well as those for the hTAS2R16 in complex with arbutin or with phenyl- $\beta$-D-glucopyranoside and the hTAS2R46/strychnine complex (Figure 1, cyan circles) feature intermediate values of recall and precision for all three docking programs.

For the other hChem-GPCR/agonist complexes, the results are not uniform among the three docking programs (for a detailed description, see Sections 2 and 3 in the Supplementary Information). In particular, the prediction for the hTAS2R1/dextromethorphan complex has precision 1.0 for HADDOCK, but recall 1.0 for AutoDock Vina and both zero recall and zero precision for Glide. Instead, that for the hOR2M3/3-mercapto-2-methyl-1-penthanol complex shows precision 1.0 for both HADDOCK and Glide, while for AutoDock Vina has both zero recall and precision. Given this high variability among complexes and docking programs, no particular trends can be drawn. Furthermore, the differences in performance may be due not only to the limitations of the docking algorithms, but also of the homology models. Nonetheless, it is noteworthy that even the group with the best docking performance (red circles in Figure 1) is able to recover only a few of the experimentally characterized binding residues.

Overall, the predictive power of the bioinformatic approach is low; only $36 \%$ (or less) of the residues were predicted correctly (see Methods), regardless of the docking program used (36, 35, and 33\% for HADDOCK, AutoDock Vina and Glide, respectively). Of course, one cannot exclude that some of the residues are exclusively involved in activation and not in the binding. Nonetheless, these are expected to be very few, as all of the mutations considered here are localized closely to the putative binding region, as known from the crystal structures of class A GPCRs (Venkatakrishnan et al., 2013). Hence, we expect that the difficulties in interpreting the experimental data are not going to change the main conclusion of this analysis, namely that the bioinformatics/docking procedure is able to recover only a few of the experimentally characterized binding residues. The low predictive power of the bioinformatics approaches, may be caused, at least in part, by the low resolution of the homology modeling techniques when the sequence identity between the target and the template is low, as it is the case for hChemGPCRs. In addition, the limited sampling of standard docking techniques might be insufficient to exhaustively explore the conformational space of the ligand bound in the binding site (see also Supplementary Information Section 1.1). Thus, the bioinformatics-based procedure calls for refinement to improve the results. An insight into this issue is offered in the next section.

\section{Molecular Dynamics-Based Refinement of Binding Predictions}

While the complete molecular simulations of all the complexes in Table 2 is beyond the scope of the present paper, it is interesting to discuss the reliability of simulations on a few specific cases, which have been already studied in our group (see Methods section). We focus on our own studies carried out using the so-called hybrid Molecular Mechanics/CoarseGrained (MM/CG) molecular dynamics simulation approach. The method, developed in our group (Neri et al., 2005, 2008; Leguebe et al., 2012; Giorgetti and Carloni, 2014; Musiani et al., 2014, 2015), focuses the computational effort in the binding site, where ligand, solvent and protein are treated with an atomistic force field, whereas the rest of the protein is described using a coarse-grained representation and the presence of the membrane is modeled by introducing appropriately designed wall potentials (Leguebe et al., 2012). Hence, the approach includes hydration at the binding site, as well as temperature fluctuations and protein flexibility, increasing the sampling of the conformational space of the ligand binding site. 
TABLE 3 | Performance assessment of the computational predictions of hChem-GPCR/agonist complexes, using the docking codes HADDOCK (Dominguez et al., 2003), AutoDock Vina (Trott and Olson, 2010), and Glide (Friesner et al., 2004) and MM/CG simulations (Marchiori et al., 2013; Sandal et al., 2015).

\begin{tabular}{|c|c|c|c|c|c|c|}
\hline $\begin{array}{l}\text { Test statistics } \\
\text { Human bitter taste receptor/agonist complex }\end{array}$ & \multicolumn{2}{|c|}{ HADDOCK } & \multicolumn{2}{|c|}{ AutoDock Vina } & \multicolumn{2}{|c|}{ Glide } \\
\hline hTAS2R4/quinine & 0.17 & 0.50 & 0.17 & 0.50 & 0.17 & 0.50 \\
\hline hTAS2R10/denatonium & 0.25 & 0.17 & 0.25 & 0.25 & 0.20 & 0.33 \\
\hline hTAS2R10/parthenolide & 0.50 & 0.20 & 0.00 & 0.00 & 0.00 & 0.00 \\
\hline hTAS2R16/phenyl- $\beta$-D-glucopyranoside & 0.17 & 0.50 & 0.17 & 0.50 & 0.25 & 0.25 \\
\hline hTAS2R16/salicin & 0.20 & 0.33 & 0.33 & 0.67 & 0.00 & 0.00 \\
\hline hTAS2R30/denatonium & 0.50 & 1.00 & 0.00 & 0.00 & 0.00 & 0.00 \\
\hline hTAS2R31/aristolochic acid & 1.00 & 0.50 & 0.00 & 0.00 & 0.00 & 0.00 \\
\hline hTAS2R38/phenylthiocarbamide & 0.00 & 0.00 & 0.00 & 0.00 & 0.00 & 0.00 \\
\hline hTAS2R46/strychnine & 0.33 & 0.60 & 0.09 & 0.50 & 0.09 & 0.50 \\
\hline Test statistics & \multicolumn{2}{|c|}{ HADDOCK } & \multicolumn{2}{|c|}{ Auto Dock Vina } & \multicolumn{2}{|c|}{ Glide } \\
\hline Human odorant receptor/agonist complex & REC & PREC & REC & PREC & REC & PREC \\
\hline hOR1A1/(R)-(-)-carvone & 0.00 & 0.00 & 0.00 & 0.00 & 0.00 & 0.00 \\
\hline hOR1A1/(S)-(+)-carvone & 0.00 & 0.00 & 0.29 & 0.67 & 0.00 & 0.00 \\
\hline hOR1A1/citronellol & 0.00 & 0.00 & 0.00 & 0.00 & 0.00 & 0.00 \\
\hline hOR2AG1/amylbutyrate & 0.20 & 1.00 & 0.40 & 1.00 & 0.25 & 0.50 \\
\hline hOR2M3/3-mercapto-2-methyl-pentan-1-ol & 0.25 & 1.00 & 0.00 & 0.00 & 0.50 & 1.00 \\
\hline hOR7D4/androstadienone & 0.16 & 1.00 & 0.16 & 1.00 & 0.17 & 1.00 \\
\hline hTAS2R46/strychnine & 1.00 & 1.00 & & & & \\
\hline
\end{tabular}

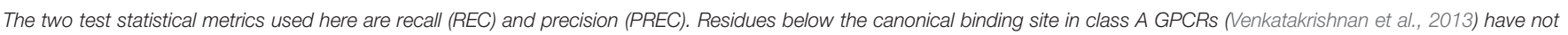
been taken into account for the test statistics calculation, as they are expected not to be involved in ligand binding.

We calculate the recall and the precision values for the $\mathrm{MM} / \mathrm{CG}$ complexes previously studied by our group [TAS2R38/PTC, TAS2R38/PROP Marchiori et al., 2013 and TAS2R46/strychnine Sandal et al., 2015] and the results turn out to be highly encouraging: both the recall and the precision values are near or equal to one (Figure $\mathbf{1 A}$ and Section 4 of the Supplementary Information). In particular, the number of FN decreases to 0 for all three complexes, improving the recall compared to the bioinformatics predictions (see Table 3). In addition, zero FPs are present for the hTAS2R46/strychnine and hTAS2R38/propylthiouracil complexes and only one for the hTAS2R38/phenylthiocarbamide complex, increasing the precision. Hence, the MM/CG simulations are able to dramatically improve the prediction results by capturing the majority of the residues crucial for ligand-receptor interaction, without introducing any significant bias, at least for the hChem-GPCR/agonist cases studied so far. Indeed, based on the predictive power of the method, several residues playing a role for ligand binding were identified and were subsequently confirmed by performing additional mutagenesis and functional experiments (Marchiori et al., 2013; Sandal et al., 2015). Systematic MM/CG simulations and extensive comparison with experiments are required to establish the predictive power of the method across all hChem-GPCRs.

\section{Receptor Activation Predictions}

Although it cannot be excluded completely that they could also be involved in ligand binding, several residues have been previously 
suggested to play a role for activation in hTAS2Rs (Biarnes et al., 2010; Pydi et al., 2014a). These are residues whose mutation causes changes in receptor's response, from abolishing activation to constitutive activation (see Supplementary Table 3). Here, we show that our bioinformatics analysis provides further support to some of these findings. Namely, we can distinguish three different groups of residues (hereafter indicated using the class A GPCR generic numbering Isberg et al., 2015).

The first group, proposed to be involved in hTAS2R1 activation, includes $\mathrm{N} 24$ and R55 (positions 1.50 and 2.50) (Singh et al., 2011a). These residues are highly conserved across hTAS2Rs (92 and 96\% respectively, see Supplementary Table 3). Moreover, we notice here that these two positions are also conserved in human class A GPCRs (98 and 87\%) and have been shown to play a role for activation across class A hGPCRs, based on mutagenesis data (see references Fenalti et al., 2014; Labadi et al., 2015 and Supplementary Table 4) and structural analyses (Venkatakrishnan et al., 2013; Tehan et al., 2014). Therefore, this may further support the claimed role of positions 1.50 and 2.50 for hTAS2Rs activation. Nonetheless, the chemical nature of residue 2.50 changes dramatically, from a positively charged Arg in hTAS2Rs to a negatively charged Asp in class A GPCRs. Hence, we suggest here distinct activation mechanisms on passing from bitter taste receptors to class A hGPCRs, yet converging at the same positions.

Next, we consider position 7.52, which has been suggested to play a role in activation for hTAS2R38 (Biarnes et al., 2010). A branched aliphatic residue (V, L or I) is present at this position in 92\% hTAS2Rs (Supplementary Table 3). This position has never been proposed to be involved in an interaction network that changes upon activation in any class A GPCR. Therefore, to blindly investigate if this is the case, we used a pool of structures of human class A GPCRs (see Table 4 and reference Venkatakrishnan et al., 2016) for which both active and inactive structures are available and carried out a graph-based structural analysis with the aim of identifying pairs of highly conserved residues that change intramolecular interactions upon activation (Tehan et al., 2014; Venkatakrishnan et al., 2016). This analysis not only confirms, as expected, all of the previously known residues important for class A GPCR activation, including positions 1.50 and 2.50 (Fenalti et al., 2014; Labadi et al., 2015), but also shows that (i) the hydrophobic nature of residue 7.52 is conserved across human class A GPCRs (Supplementary Table 5), and (ii) this residue does change its interactions

TABLE 4 | Active/inactive pairs of mammalian class A GPCR crystal structures used for the graph-based structural analysis.

\begin{tabular}{llll}
\hline Class A GPCR & Active state & Inactive state & Species \\
\hline B2-adrenergic receptor & $2 \mathrm{RH} 1(2.40)$ & $3 \mathrm{SN6}(3.20)$ & human \\
M2 muscarinic receptor & $3 \mathrm{UON}(3.00)$ & $4 \mathrm{MQS}(3.50)$ & human \\
adenosine A2A receptor & $3 \mathrm{EML}(2.60)$ & $5 \mathrm{G} 53(3.40)$ & human \\
rhodopsin & 1GZM (2.65) & $3 \mathrm{PQR}(2.85)$ & bovine \\
$\mu$-opioid receptor & $4 \mathrm{DKL}(2.80)$ & $5 \mathrm{C} 1 \mathrm{M}(2.10)$ & murine \\
\hline
\end{tabular}

The corresponding PDB codes are listed, together with the crystallographic resolution (between parentheses, in $\AA$ ). upon activation (Supplementary Figure 5). This observation is in agreement with previous experimental data showing that mutations at this position modify the receptor activity in class A GPCRs (see Supplementary Table 4). Therefore, our analysis not only confirms that position 7.52 is important for activation in hTAS2Rs, but also suggests for the first time, from a structural point of view, that this position is actively involved in a network of residues that changes upon activation in class A GPCRs.

The final group of residues proposed to be involved in activation are I27 in hTAS2R1 (position 1.53) (Singh et al., 2011a), as well as S285 and H214 (positions 7.50 and 5.63) and three residues in the intracellular loop ICL3 (Q216, V234, M237) in hTAS2R4 (Pydi et al., 2012, 2014a). Some of these positions $(1.53,5.63$ and 7.50$)$ are highly or fairly well conserved across hTAS2Rs (96, 96, and 68\%, respectively). Interestingly, position 7.50 bears either a Ser $(68 \%)$ or a Pro $(28 \%)$ in hTAS2Rs, while, in human class A GPCRs, Pro is highly conserved (95\%). This position belongs to the conserved TM7 motif NPXXY that is essential for class A GPCRs' activation (Fritze et al., 2003; Audet and Bouvier, 2012; Trzaskowski et al., 2012), but there are no experimental data available for this residue. In the case of ICL3 residues, they do not present high conservation values and a role in activation for these positions in human class A GPCRs has not been suggested so far (and does not emerge from our analysis). This is probably due to their intracellular location in a highly variable region and their likely participation in G-protein binding (Pydi et al., 2014a; Venkatakrishnan et al., 2016) and G $\alpha$-subunit selectivity (Flock et al., 2017).

\section{CONCLUSIONS}

Structural predictions of human GPCRs are a challenge for computational biologists (Michino et al., 2009; Katritch et al., 2010; Kufareva et al., 2011, 2014; Cavasotto and Palomba, 2015). Integration of experimental and computational information is fundamental to understand ligand binding to these proteins (Thomas et al., 2014; Munk et al., 2016), and in particular to hChem-GPCRs (Charlier et al., 2013; Di Pizio and Niv, 2014; Suku et al., 2017). The reliability of the structural predictions must be validated not only by comparison against previously published experimental data, but also by performing additional site-directed mutagenesis and functional experiments.

Here, we have presented a systematic structural bioinformatics study of all human bitter taste and odorant receptors that feature available experimental data. To the best of our knowledge, this is the first time that such comprehensive study has been undertaken. State-of-the-art bioinformatics approaches, combined with docking algorithms, show clear limitations in the structural predictions of ligand binding determinants. Indeed, several of the residues experimentally shown to be important for ligand binding could not be identified (i.e., low recall), and residues actually not involved in ligand interaction were suggested as so (i.e., low precision) (see Figure 1). These shortcomings are probably due to a variety of factors, including the low sequence identity between the class A GPCR 
templates and the hChem-GPCR targets, as well as the limited sampling of the docking algorithms. Similarly, previous studies on GPCR/ligand complexes have suggested that the sequence identity lower threshold for accurate prediction of binding modes is between 30\% (Beuming and Sherman, 2012) and $40 \%$ (Kufareva et al., 2011). As mentioned in the Introduction, a possible way to overcome, at least in part, these limitations is the refinement of the predictions using advanced docking methods or molecular dynamics simulations able to better sample the conformational space (Gelis et al., 2012; Lai and Crasto, 2012; Charlier et al., 2013; Lai et al., 2014). As an example from our own lab, we have shown that the Molecular Mechanics/Coarse Grained (MM/CG) approach developed in our group does improve the quality of the predictions for the three hChemGPCR/ligand complexes studied so far (Marchiori et al., 2013; Sandal et al., 2015). Similar considerations were suggested for GPCR/ligand complexes in general by Cavasotto and Palomba (2015). Upon reviewing several predictions of the GPCR Dock experiments (Michino et al., 2009; Kufareva et al., 2011, 2014), they concluded that homology modeling combined with docking can be considered just as an initial step in the characterization of ligand-receptor interactions, and that the bioinformatics-based predictions can benefit of refinement with molecular dynamics.

Furthermore, our bioinformatics analysis supports previous claims that residues in positions 1.50, 2.50, and 7.52 might be involved (at least in part) in the activation of hTAS2Rs. Hence, despite the probable differences in the activation mechanisms, some of the activation-related features could be shared between hChem-GPCRs and other class A human GPCRs ${ }^{[8]}$.

\section{METHODS}

\section{Homology Modeling}

The structures of the human chemosensory receptors (hChemGPCRs, Table 2 and Supplementary Table 6) were predicted using our GOMoDo webserver (Sandal et al., 2013), following the protocol in references (Marchiori et al., 2013; Sandal et al., 2015).

First, we downloaded all of the available sequences for hTAS2Rs (25) and hORs (464) from the Pfam database (Bateman et al., 2004). The number of hTAS2Rs is established (Meyerhof et al., 2010). In contrast, different numbers have been proposed for hORs (Malnic et al., 2004; Young et al., 2008). This required great care in selecting the hORs used for the corresponding multiple sequence alignment (MSA). Specifically, before performing the alignment, we removed hOR sequences not manually annotated and reviewed, as well as those corresponding to pseudogenes. In addition, once the MSA is generated (see below), we discarded hOR sequences containing large gaps or lacking highly conserved features (Table 1). Indeed, these sequences correspond most likely to not annotated pseudogenes or to open reading frames wrongly predicted to code for hORs.

The 25 hTAS2R sequences and the remaining 411 hOR sequences are aligned using PROMALS (Pei et al., 2007). The resulting two MSAs (see Supplementary Information Section 1.1) were manually curated in order to ensure the alignment of the common conserved features of each chemosensory receptor family. These include: (i) the X.50 position (Isberg et al., 2015); (ii) the conserved structural motifs (Venkatakrishnan et al., 2013; Pydi et al., 2014a, 2016; de March et al., 2015a; Di Pizio et al., 2016) (see Table 1); and, only for hORs, (iii) the two disulfide bridges present in most ( $\sim 94 \%)$ hORs. These involve sulfur atoms of two cysteines of the extracellular loop ECL2 and sulfur atoms of cysteines in ECL2 and TM3 (Cook et al., 2009; Charlier et al., 2013; Kim and Goddard, 2014).

Then, the MSAs were input into the GOMoDo webserver to generate a Hidden Markov Model (HMM) for each subfamily of hChem-GPCRs. The resulting HMMs of the target hChemGPCRs were aligned against all the HMMs of the GPCR templates available in the GOMoDo webserver, employing HHsearch 2.0.16 (Soding et al., 2005). The use of profile HMMs is known to improve the target-template alignment when dealing with distant homologs (Soding, 2005), as it is the case with the target hChem-GPCRs. 100 models were generated for each target-template pair (see Supplementary Information Section 1.2), using MODELLER 9v10 (Webb and Sali, 2016). The receptor models were then evaluated relying on MODELLER quality scores (low normalized DOPE and high GA341 values) (Melo et al., 2002; Shen and Sali, 2006).

Among all the templates, the human $\beta 2$ adrenoceptor (PDB code: 4LDE, resolution: $2.79 \AA$ ) was identified as the most suitable one (see also Results section). On one hand, the models carried out with $\beta 2$ adrenoceptor show better MODELLER quality scores (Melo et al., 2002; Shen and Sali, 2006) for all the hChem-GPCRs object of this study. On the other, this template was solved in a fully active state (Venkatakrishnan et al., 2016), which is expected to be the agonist-bound conformational state.

The template-target alignments were then checked and refined by hand, in order to preserve the conserved features of class A GPCRs (see Table 1). Then, 100 new models based on the manually curated alignment between the target hChem-GPCR and the $4 \mathrm{LDE}$ template were regenerated, using a standalone version of the MODELLER 9v10 program (Webb and Sali, 2016), and re-evaluated following the procedure described above. For each receptor, the selection of the model was based on (i) the MODELLER quality scores (Melo et al., 2002; Shen and Sali, 2006), and (ii) preservation of the secondary structure of the TM helices. The chosen model was further considered for docking.

Throughout the manuscript, we use the GPCRdb generic number position (Isberg et al., 2015) (except where specified), which generalizes the Ballesteros-Weinstein numbering (Ballesteros and Weinstein, 1995), to have a coherent numeration of the residues between human chemosensory GPCRs and other class A GPCRs. In particular, we used the GPCRdb numbering scheme of the selected template, the $\beta 2$ adrenoceptor (Supplementary Table 1).

\section{Molecular Docking}

The agonists in Table 2 were docked on the final receptor models using (i) HADDOCK (Dominguez et al., 2003) through the GOMoDO webserver (Sandal et al., 2013) (version 2.1), (ii) AutoDock Vina (Trott and Olson, 2010) through Chimera (Pettersen et al., 2004) (version 1.11.2), and (iii) Glide (Gridbased Ligand Docking with Energetics) (Friesner et al., 2004) 
through the Schrodinger Suite (version 2017-1). All the dockings presented here are blind, i.e., no experimental data was used to guide them. The ligand structures and parameters were obtained from the ZINC database (Irwin and Shoichet, 2005) and the PRODRG webserver (Schuttelkopf and van Aalten, 2004), respectively.

For the prediction-guided HADDOCK docking, putative binding cavity residues (see Supplementary Table 7) were predicted with fpocket (Le Guilloux et al., 2009), and used as active residues to define ambiguous interaction restraints (AIRs). For each ligand, 1000 random structures were generated through initial rigid docking. Then, the structures were ranked and the best 200 complexes underwent refinement with both ligand and receptor treated as flexible (first by simulated annealing, and then by refinement in explicit water). The resulting receptor-agonist complexes were clustered using an RMSD cutoff of $2.0 \AA$ and the complex of the most populated cluster with the lowest energy was chosen for further analysis.

For AutoDock Vina docking, a grid which covers all the fpocket predicted residues was created and the ligands were docked inside the grid. Docking was performed with default parameters (Trott and Olson, 2010) and considering the receptor as rigid. The best complex, i.e., the one with the lowest energy scoring function, was chosen for further analysis.

Finally, for the Glide docking, the grid was built using the same criterium as for AutoDock Vina. 50 binding poses have been produced and ranked according to the Emodel score, a score wellsuited for comparing different binding poses of the same ligand (Friesner et al., 2004). The binding pose with the lowest Emodel has been selected.

\section{Statistical Analysis}

The residues involved in protein-ligand interactions were identified based on two criteria. As a first step, we use a distance threshold, in which an atomic contact between protein and ligand is considered to be present when their distance is below $5.5 \AA$ (i.e., the sum of the van der Waals carbon radii plus the water molecule diameter (Lee and Richards, 1971; Bohacek and McMartin, 1992; Graziano, 1998). In the second step, we apply a chemical definition, to keep only those contacts that do correspond to classical chemical interactions (i.e., hydrogen bonds, salt bridges, stacking or hydrophobic contacts, etc.) upon visual inspection. Using these two criteria, we analyze the number of true positives (TP), false positives (FP), true negatives (TN) and false negatives (FN) for all ligand-receptor complexes (see Figure 2), by comparison with the experimental data (Supplementary Table 1). Only mutants located in the top half of the receptor are taken into account because this is the location of the canonical orthosteric binding site of class A GPCRs (Venkatakrishnan et al., 2013). Using the aforementioned test outcomes, we calculate the corresponding values of precision,

$$
\mathrm{PREC}=\mathrm{TP} /(\mathrm{TP}+\mathrm{FP})
$$

and recall,

$$
\mathrm{REC}=\mathrm{TP} /(\mathrm{TP}+\mathrm{FN})
$$

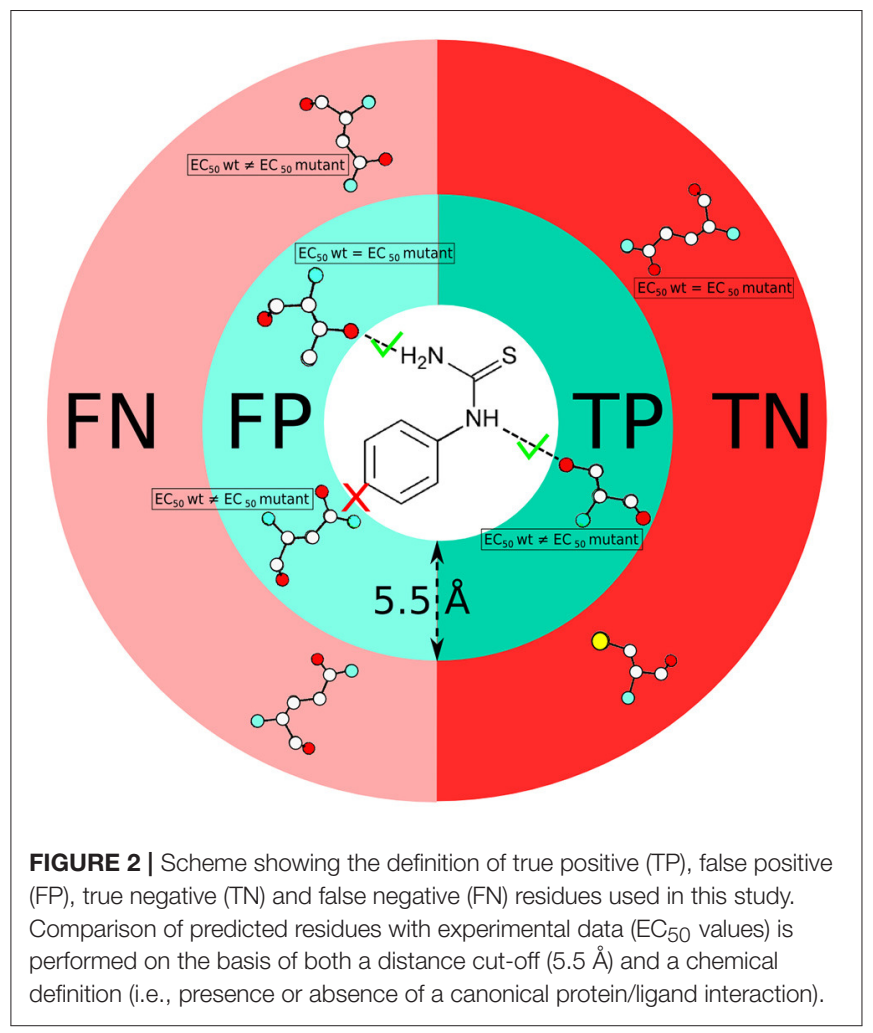

in order to assess the reliability of our docking results. These standard statistical parameters are usually employed for method performance assessment (Raghavan et al., 1989; Manning and Schütze, 1999; Davis and Goadrich, 2006; Saito and Rehmsmeier, 2015). Here, the precision is given by the ratio between the experimentally characterized binding residues that the bioinformatics approach is able to capture (TP) and other residues that docking wrongly considers as important in ligandreceptor interaction (FP). On the other hand, the recall is the ratio between TP and experimentally characterized binding residues that the bioinformatics approach is not able to capture (FN). Both precision and recall are normalized and thus values equal to one suggest optimum performance of the method. In addition, in order to evaluate the predictive power of the bioinformatics approach, we calculate the following percentage:

$(\mathrm{TP}+\mathrm{TN}) * 100 /($ total number of experimental data in the top half of the receptor)

which is not aimed at evaluating the performance of the individual docking programs, but the combination of homology modeling and docking.

\section{Multiscale Molecular Dynamics Simulations}

As written above, the simulations analyzed here correspond to our previous works on hTAS2R38 in complex with two of its agonists (PROP and PTC) (Marchiori et al., 2013) and hTAS2R46 in complex with strychnine (Sandal et al., 
2015). These simulations were carried out with a Molecular Mechanics/Coarse-Grained (MM/CG) method developed in our group. In this approach, the MM part (ligand and surrounding protein residues and water molecules) is treated with the GROMOS96 atomistic force field (Scott et al., 1999), whereas the CG part (the rest of the protein, including only the C $\alpha$ atoms) is described using a Go-like model (Go and Abe, 1981). The two regions are connected at the interface by using a coupling scheme (Neri et al., 2005, 2008). The presence of the membrane is mimicked by introducing five repulsive walls (Leguebe et al., 2012; Giorgetti and Carloni, 2014; Musiani et al., 2014, 2015). For each hTAS2R38 complex (PROP or PTC), two replicas (with different velocities) were run for $0.6 \mu \mathrm{s}$ each (Marchiori et al., 2013). For the hTAS2R46/strychnine complex, three replicas were run for $1 \mu$ s each (Sandal et al., 2015).

\section{Receptor Activation Predictions}

The sequences of all human class A GPCRs (698) were downloaded from the Pfam database and aligned with PROMALS (Pei et al., 2007). Conserved motifs were identified using in-house scripts written in Python.

The structural analysis was performed on the X-ray structures of human class A GPCRs crystallized both in the active and inactive states, listed in Table 4. We generated a contact map for all independent atomic distances (excluding backbone atoms) and then defined a contact between a pair of residues as formed when the distance between any two atoms of the residue pair is shorter than the sum of their van der Waals radii, as defined in reference (Venkatakrishnan et al., 2016). For completeness

\section{REFERENCES}

Abaffy, T. (2015). Human olfactory receptors expression and their role in nonolfactory tissues-a mini-review. J. Pharmacogenomics Pharmacoproteomics 6:1. doi: 10.4172/2153-0645.1000152

Adappa, N. D., Zhang, Z., Palmer, J. N., Kennedy, D. W., Doghramji, L., Lysenko, A., et al. (2014). The bitter taste receptor T2R38 is an independent risk factor for chronic rhinosinusitis requiring sinus surgery. Int. Forum Allergy Rhinol. 4, 3-7. doi: 10.1002/alr.21253

Adler, E., Hoon, M. A., Mueller, K. L., Chandrashekar, J., Ryba, N. J., and Zuker, C. S. (2000). A novel family of mammalian taste receptors. Cell 100, 693-702. doi: 10.1016/S0092-8674(00)80705-9

Angel, T. E., Chance, M. R., and Palczewski, K. (2009). Conserved waters mediate structural and functional activation of family A (rhodopsin-like) G protein-coupled receptors. Proc. Natl. Acad. Sci. U.S.A. 106, 8555-8560. doi: 10.1073/pnas.0903545106

Ansoleaga, B., Garcia-Esparcia, P., Llorens, F., Moreno, J., Aso, E., and Ferrer, I. (2013). Dysregulation of brain olfactory and taste receptors in AD, PSP and CJD, and AD-related model. Neuroscience 248, 369-382. doi: 10.1016/j.neuroscience.2013.06.034

Ansoleaga, B., Garcia-Esparcia, P., Pinacho, R., Haro, J. M., Ramos, B., and Ferrer, I. (2015). Decrease in olfactory and taste receptor expression in the dorsolateral prefrontal cortex in chronic schizophrenia. J. Psychiatr. Res. 60, 109-116. doi: 10.1016/j.jpsychires.2014.09.012

Audet, M., and Bouvier, M. (2012). Restructuring G-protein-coupled receptor activation. Cell 151, 14-23. doi: 10.1016/j.cell.2012.09.003

Bahia, M. S., Nissim, I., and Niv, M. Y. (2017). Bitterness prediction in-silico: a step towards better drugs. Int. J. Pharm. doi: 10.1016/j.ijpharm.2017.03.076. [Epub ahead of print]. and in line with references (Venkatakrishnan et al., 2013; Tehan et al., 2014), this analysis was also performed on the other two mammalian receptors solved in both active and inactive states, i.e., bovine rhodopsin (1GZM/3PQR) and murine $\mu$ opioid receptor $(4 \mathrm{DKL} / 5 \mathrm{C} 1 \mathrm{M})$, confirming the results obtained for the human structures (see Results section).

\section{AUTHOR CONTRIBUTIONS}

Wrote the paper: FF, ES, MAP, AG, and PC; analyzed the data: FF, ES, MAP, AG, and PC; designed the experiments: FF, ES, MAP, AG, SC, and PC; conducted the experiments: FF, ES, MAP, and AG; provided data that started the project: SC. All authors read and approved the final manuscript.

\section{ACKNOWLEDGMENTS}

We thank Luciano Navarini (Illy Caffe', Trieste, Italy) for scientific discussions. The authors acknowledge the financial support of the "Ernesto Illy Foundation" (Trieste, Italy). One of us (PC) is also grateful for grants from the BioExcel Center of Excellence and the Human Brain Project (European Union's Horizon 2020 Framework Programme for Research and Innovation).

\section{SUPPLEMENTARY MATERIAL}

The Supplementary Material for this article can be found online at: http://journal.frontiersin.org/article/10.3389/fmolb. 2017.00063/full\#supplementary-material

Baker, D., and Sali, A. (2001). Protein structure prediction and structural genomics. Science 294, 93-96. doi: 10.1126/science.1065659

Ballesteros, J. A., and Weinstein, H. (1995). [19] Integrated methods for the construction of three-dimensional models and computational probing of structure-function relations in G protein-coupled receptors. Methods Neurosci. 25, 366-428. doi: 10.1016/S1043-9471(05)80049-7

Bateman, A., Coin, L., Durbin, R., Finn, R. D., Hollich, V., Griffiths-Jones, S., et al. (2004). The Pfam protein families database. Nucleic Acids Res. 32, D138-D141. doi: 10.1093/nar/gkh121

Behrens, M., and Meyerhof, W. (2009). Mammalian bitter taste perception. Results Probl. Cell Differ. 47, 203-220. doi: 10.1007/400_2008_5

Behrens, M., and Meyerhof, W. (2011). Gustatory and extragustatory functions of mammalian taste receptors. Physiol. Behav. 105, 4-13. doi: 10.1016/j.physbeh.2011.02.010

Benson, P. W., Hooker, J. B., Koch, K. L., and Weinberg, R. B. (2012). Bitter taster status predicts susceptibility to vection-induced motion sickness and nausea. Neurogastroenterol. Motil 24, 134-140, e186. doi: 10.1111/j.1365-2982.2011.01842.x

Berridge, M. J., Lipp, P., and Bootman, M. D. (2000). The versatility and universality of calcium signalling. Nat. Rev. Mol. Cell Biol. 1, 11-21. doi: $10.1038 / 35036035$

Beuming, T., and Sherman, W. (2012). Current assessment of docking into GPCR crystal structures and homology models: successes, challenges, and guidelines. J. Chem. Inf. Model. 52, 3263-3277. doi: 10.1021/ci30 $0411 b$

Biarnes, X., Marchiori, A., Giorgetti, A., Lanzara, C., Gasparini, P., Carloni, P., et al. (2010). Insights into the binding of Phenyltiocarbamide (PTC) agonist to its target human TAS2R38 bitter receptor. PLoS ONE 5:e12394. doi: 10.1371/journal.pone.0012394 
Bohacek, R. S., and McMartin, C. (1992). Definition and display of steric, hydrophobic, and hydrogen-bonding properties of ligand binding sites in proteins using Lee and Richards accessible surface: validation of a highresolution graphical tool for drug design. J. Med. Chem. 35, 1671-1684. doi: 10.1021/jm00088a002

Born, S., Levit, A., Niv, M. Y., Meyerhof, W., and Behrens, M. (2013). The human bitter taste receptor TAS2R10 is tailored to accommodate numerous diverse ligands. J. Neurosci. 33, 201-213. doi: 10.1523/JNEUROSCI.3248-12.2013

Braun, T., Voland, P., Kunz, L., Prinz, C., and Gratzl, M. (2007). Enterochromaffin cells of the human gut: sensors for spices and odorants. Gastroenterology 132, 1890-1901. doi: 10.1053/j.gastro.2007.02.036

Breer, H., Eberle, J., Frick, C., Haid, D., and Widmayer, P. (2012). Gastrointestinal chemosensation: chemosensory cells in the alimentary tract. Histochem. Cell Biol. 138, 13-24. doi: 10.1007/s00418-012-0954-z

Brockhoff, A., Behrens, M., Niv, M. Y., and Meyerhof, W. (2010). Structural requirements of bitter taste receptor activation. Proc. Natl. Acad. Sci. U.S.A. 107, 11110-11115. doi: 10.1073/pnas.0913862107

Broomhead, N. K., and Soliman, M. E. (2017). Can we rely on computational predictions to correctly identify ligand binding sites on novel protein drug targets? Assessment of binding site prediction methods and a protocol for validation of predicted binding sites. Cell Biochem. Biophys. 75, 15-23. doi: 10.1007/s12013-016-0769-y

Bruch, R. C. (1996). Phosphoinositide second messengers in olfaction. Comp. Biochem. Physiol. B Biochem. Mol. Biol. 113, 451-459. doi: 10.1016/0305-0491(95)02040-3

Buck, L., and Axel, R. (1991). A novel multigene family may encode odorant receptors: a molecular basis for odor recognition. Cell 65, 175-187. doi: 10.1016/0092-8674(91)90418-X

Busato, M., and Giorgetti, A. (2016). Structural modeling of G-protein coupled receptors: an overview on automatic web-servers. Int. J. Biochem. Cell Biol. 77, 264-274. doi: 10.1016/j.biocel.2016.04.004

Busse, D., Kudella, P., Gruning, N. M., Gisselmann, G., Stander, S., Luger, T., et al. (2014). A synthetic sandalwood odorant induces wound-healing processes in human keratinocytes via the olfactory receptor OR2AT4. J. Invest. Dermatol. 134, 2823-2832. doi: 10.1038/jid.2014.273

Cavasotto, C. N., and Palomba, D. (2015). Expanding the horizons of G protein-coupled receptor structure-based ligand discovery and optimization using homology models. Chem. Commun. (Camb) 51, 13576-13594. doi: 10.1039/C5CC05050B

Chandrashekar, J., Hoon, M. A., Ryba, N. J. P., and Zuker, C. S. (2006). The receptors and cells for mammalian taste. Nature 444, 288-294. doi: $10.1038 /$ nature 05401

Chandrashekar, J., Mueller, K. L., Hoon, M. A., Adler, E., Feng, L., Guo, W., et al. (2000). T2Rs function as bitter taste receptors. Cell 100, 703-711. doi: 10.1016/S0092-8674(00)80706-0

Charlier, L., Topin, J., de March, C. A., Lai, P. C., Crasto, C. J., and Golebiowski, J. (2013). Molecular modelling of odorant/olfactory receptor complexes. Methods Mol. Biol. 1003, 53-65. doi: 10.1007/978-1-62703-377-0_4

Chen, Y. C. (2015). Beware of docking! Trends Pharmacol. Sci. 36, 78-95. doi: 10.1016/j.tips.2014.12.001

Chothia, C., and Lesk, A. M. (1986). The relation between the divergence of sequence and structure in proteins. EMBO J. 5, 823-826.

Clapp, T. R., Stone, L. M., Margolskee, R. F., and Kinnamon, S. C. (2001). Immunocytochemical evidence for co-expression of Type III IP3 receptor with signaling components of bitter taste transduction. BMC Neurosci. 2:6. doi: 10.1186/1471-2202-2-6

Colquhoun, D. (1998). Binding, gating, affinity and efficacy: the interpretation of structure-activity relationships for agonists and of the effects of mutating receptors. Br. J. Pharmacol. 125, 924-947. doi: 10.1038/sj.bjp.07 02164

Cook, B. L., Steuerwald, D., Kaiser, L., Graveland-Bikker, J., Vanberghem, M., Berke, A. P., et al. (2009). Large-scale production and study of a synthetic G protein-coupled receptor: human olfactory receptor 17-4. Proc. Natl. Acad. Sci. U.S.A. 106, 11925-11930. doi: 10.1073/pnas.0811089106

Cvicek, V., Goddard, W. A. III., and Abrol, R. (2016). Structure-based sequence alignment of the transmembrane domains of all human GPCRs: phylogenetic, structural and functional implications. PLoS Comput. Biol. 12:e1004805. doi: 10.1371/journal.pcbi.1004805
Dai, W., You, Z., Zhou, H., Zhang, J., and Hu, Y. (2011). Structure-function relationships of the human bitter taste receptor hTAS2R1: insights from molecular modeling studies. J. Recept. Signal Transduct. Res. 31, 229-240. doi: 10.3109/10799893.2011.578141

Davis, J., and Goadrich, M. (2006). The relationship between precision-recall and ROC curves," in Proceedings of the 23rd International Conference on Machine Learning. (Pittsburgh, PA: ACM), 233-240.

de March, C. A., Kim, S. K., Antonczak, S., Goddard, W. A. III., and Golebiowski, J. (2015a). G protein-coupled odorant receptors: from sequence to structure. Protein Sci. 24, 1543-1548. doi: 10.1002/pro.2717

de March, C. A., Yu, Y., Ni, M. J., Adipietro, K. A., Matsunami, H., Ma, M., et al. (2015b). Conserved residues control activation of mammalian g protein-coupled odorant receptors. J. Am. Chem. Soc. 137, 8611-8616. doi: $10.1021 /$ jacs.5b04659

Di Pizio, A., Levit, A., Slutzki, M., Behrens, M., Karaman, R., and Niv, M. Y. (2016). Comparing Class A GPCRs to bitter taste receptors: structural motifs, ligand interactions and agonist-to-antagonist ratios. Methods Cell Biol. 132, 401-427. doi: 10.1016/bs.mcb.2015.10.005

Di Pizio, A., and Niv, M. Y. (2014). Computational Studies of Smell and Taste Receptors. Isr. J. Chem. 54, 1205-1218. doi: 10.1002/ijch.201400027

Dominguez, C., Boelens, R., and Bonvin, A. M. (2003). HADDOCK: a proteinprotein docking approach based on biochemical or biophysical information. J. Am. Chem. Soc. 125, 1731-1737. doi: 10.1021/ja026939x

Durzynski, L., Gaudin, J. C., Myga, M., Szydlowski, J., Gozdzicka-Jozefiak, A., and Haertle, T. (2005). Olfactory-like receptor cDNAs are present in human lingual cDNA libraries. Biochem. Biophys. Res. Commun. 333, 264-272. doi: 10.1016/j.bbrc.2005.05.085

Eramian, D., Eswar, N., Shen, M. Y., and Sali, A. (2008). How well can the accuracy of comparative protein structure models be predicted? Protein Sci. 17, 1881-1893. doi: 10.1110/ps.036061.108

Feldmesser, E., Olender, T., Khen, M., Yanai, I., Ophir, R., and Lancet, D. (2006). Widespread ectopic expression of olfactory receptor genes. BMC Genomics 7:121. doi: 10.1186/1471-2164-7-121

Fenalti, G., Giguere, P. M., Katritch, V., Huang, X. P., Thompson, A. A., Cherezov, V., et al. (2014). Molecular control of $\delta$-opioid receptor signalling. Nature 506, 191-196. doi: 10.1038/nature12944

Ferrer, I., Garcia-Esparcia, P., Carmona, M., Carro, E., Aronica, E., Kovacs, G. G., et al. (2016). Olfactory receptors in non-chemosensory organs: the nervous system in health and disease. Front. Aging Neurosci. 8:163. doi: 10.3389 /fnagi.2016.00163

Firestein, S. (2001). How the olfactory system makes sense of scents. Nature 413 211-218. doi: $10.1038 / 35093026$

Firestein, S. (2005). A nobel nose: the 2004 nobel prize in physiology and medicine. Neuron 45, 333-338. doi: 10.1016/j.neuron.2005.01.021

Flegel, C., Manteniotis, S., Osthold, S., Hatt, H., and Gisselmann, G. (2013). Expression profile of ectopic olfactory receptors determined by deep sequencing. PLoS ONE 8:e55368. doi: 10.1371/journal.pone.0055368

Flegel, C., Vogel, F., Hofreuter, A., Schreiner, B. S., Osthold, S., Veitinger, S., et al. (2015). Characterization of the olfactory receptors expressed in human spermatozoa. Front. Mol. Biosci. 2:73. doi: 10.3389/fmolb.2015.00073

Flock, T., Hauser, A. S., Lund, N., Gloriam, D. E., Balaji, S., and Babu, M. M. (2017). Selectivity determinants of GPCR-G-protein binding. Nature 545, 317-322. doi: 10.1038 /nature22070

Foster, S. R., Roura, E., and Thomas, W. G. (2014). Extrasensory perception: odorant and taste receptors beyond the nose and mouth. Pharmacol. Ther. 142, 41-61. doi: 10.1016/j.pharmthera.2013.11.004

Fredriksson, R., Lagerstrom, M. C., Lundin, L. G., and Schioth, H. B. (2003). The G-protein-coupled receptors in the human genome form five main families. Phylogenetic analysis, paralogon groups, and fingerprints. Mol. Pharmacol. 63, 1256-1272. doi: 10.1124/mol.63.6.1256

Friesner, R. A., Banks, J. L., Murphy, R. B., Halgren, T. A., Klicic, J. J., Mainz, D. T., et al. (2004). Glide: a new approach for rapid, accurate docking and scoring. 1. Method and assessment of docking accuracy. J. Med. Chem. 47, 1739-1749. doi: $10.1021 / \mathrm{jm} 0306430$

Fritze, O., Filipek, S., Kuksa, V., Palczewski, K., Hofmann, K. P., and Ernst, O. P. (2003). Role of the conserved $\operatorname{NPxxY}(\mathrm{x}) 5,6 \mathrm{~F}$ motif in the rhodopsin ground state and during activation. Proc. Natl. Acad. Sci. U.S.A. 100, 2290-2295. doi: $10.1073 /$ pnas. 0435715100 
Gaida, M. M., Mayer, C., Dapunt, U., Stegmaier, S., Schirmacher, P., Wabnitz, G. H., et al. (2016). Expression of the bitter receptor T2R38 in pancreatic cancer: localization in lipid droplets and activation by a bacteria-derived quorumsensing molecule. Oncotarget 7, 12623-12632. doi: 10.18632/oncotarget.7206

Garcia-Esparcia, P., Schluter, A., Carmona, M., Moreno, J., Ansoleaga, B., Torrejon-Escribano, B., et al. (2013). Functional genomics reveals dysregulation of cortical olfactory receptors in Parkinson disease: novel putative chemoreceptors in the human brain. J. Neuropathol. Exp. Neurol. 72, 524-539. doi: 10.1097/NEN.0b013e318294fd76

Geithe, C., Protze, J., Kreuchwig, F., Krause, G., and Krautwurst, D. (2017). Structural determinants of a conserved enantiomer-selective carvone binding pocket in the human odorant receptor OR1A1. Cell Mol. Life Sci. doi: 10.1007/s00018-017-2576-z. [Epub ahead of print].

Gelis, L., Wolf, S., Hatt, H., Neuhaus, E. M., and Gerwert, K. (2012). Prediction of a ligand-binding niche within a human olfactory receptor by combining sitedirected mutagenesis with dynamic homology modeling. Angew. Chem. Int. Ed Engl. 51, 1274-1278. doi: 10.1002/anie.201103980

Giorgetti, A., and Carloni, P. (2014). "Molecular mechanics/coarse-grained models," in Protein Modelling, ed G. Náray-Szabó (Cham, CH: Springer International Publishing), 165-174.

Go, N., and Abe, H. (1981). Noninteracting local-structure model of folding and unfolding transition in globular proteins. I. Formulation. Biopolymers 20, 991-1011. doi: 10.1002/bip.1981.360200511

Goto, T., Salpekar, A., and Monk, M. (2001). Expression of a testis-specific member of the olfactory receptor gene family in human primordial germ cells. Mol. Hum. Reprod. 7, 553-558. doi: 10.1093/molehr/7. 6.553

Graziano, G. (1998). On the size dependence of hydrophobic hydration. J. Chem. Soc. Faraday Trans. 94, 3345-3352. doi: 10.1039/a805733h

Griffin, C. A., Kafadar, K. A., and Pavlath, G. K. (2009). MOR23 promotes muscle regeneration and regulates cell adhesion and migration. Dev. Cell 17, 649-661. doi: 10.1016/j.devcel.2009.09.004

Grison, A., Zucchelli, S., Urzi, A., Zamparo, I., Lazarevic, D., Pascarella, G., et al. (2014). Mesencephalic dopaminergic neurons express a repertoire of olfactory receptors and respond to odorant-like molecules. BMC Genomics 15:729. doi: 10.1186/1471-2164-15-729

Guerrero-Flores, H., Apresa-Garcia, T., Garay-Villar, O., Sanchez-Perez, A., Flores-Villegas, D., Bandera-Calderon, A., et al. (2017). A non-invasive tool for detecting cervical cancer odor by trained scent dogs. BMC Cancer 17:79. doi: 10.1186/s12885-016-2996-4

Hoon, M. A., Adler, E., Lindemeier, J., Battey, J. F., Ryba, N. J., and Zuker, C. S. (1999). Putative mammalian taste receptors: a class of tastespecific GPCRs with distinct topographic selectivity. Cell 96, 541-551. doi: 10.1016/S0092-8674(00)80658-3

Irwin, J. J., and Shoichet, B. K. (2005). ZINC- a free database of commercially available compounds for virtual screening. J. Chem. Info. Model. 45, 177-182. doi: $10.1021 / \mathrm{ci} 049714$

Isberg, V., de Graaf, C., Bortolato, A., Cherezov, V., Katritch, V., Marshall, F. H., et al. (2015). Generic GPCR residue numbers-aligning topology maps while minding the gaps. Trends Pharmacol. Sci. 36, 22-31. doi: 10.1016/j.tips.2014.11.001

Janssen, S., Laermans, J., Verhulst, P. J., Thijs, T., Tack, J., and Depoortere, I. (2011). Bitter taste receptors and alpha-gustducin regulate the secretion of ghrelin with functional effects on food intake and gastric emptying. Proc. Natl. Acad. Sci. U.S.A. 108, 2094-2099. doi: 10.1073/pnas.1011508108

Jenkins, P. M., McEwen, D. P., and Martens, J. R. (2009). Olfactory cilia: linking sensory cilia function and human disease. Chem. Senses 34, 451-464. doi: 10.1093/chemse/bjp020

Kang, N., and Koo, J. (2012). Olfactory receptors in non-chemosensory tissues. BMB Rep. 45, 612-622. doi: 10.5483/BMBRep.2012.45.11.232

Katritch, V., Rueda, M., Lam, P. C., Yeager, M., and Abagyan, R. (2010). GPCR 3D homology models for ligand screening: lessons learned from blind predictions of adenosine A2a receptor complex. Proteins 78, 197-211. doi: $10.1002 /$ prot.22507

Keller, A., Gerkin, R. C., Guan, Y., Dhurandhar, A., Turu, G., Szalai, B., et al. (2017). Predicting human olfactory perception from chemical features of odor molecules. Science 355, 820-826. doi: 10.1126/science. aal2014
Keller, A., Zhuang, H., Chi, Q., Vosshall, L. B., and Matsunami, H. (2007). Genetic variation in a human odorant receptor alters odour perception. Nature 449 , 468-472. doi: $10.1038 /$ nature 06162

Kim, S. K., and Goddard, W. A. III. (2014). Predicted 3D structures of olfactory receptors with details of odorant binding to OR1G1. J. Comput. Aided Mol. Des. 28, 1175-1190. doi: 10.1007/s10822-014-9793-4

Ko, H. J., and Park, T. H. (2016). Bioelectronic nose and its application to smell visualization. J. Biol. Eng. 10, 17. doi: 10.1186/s13036-016-0041-4

Kobilka, B. K. (2007). G protein coupled receptor structure and activation. Biochim. Biophys. Acta 1768, 794-807. doi: 10.1016/j.bbamem.2006.10.021

Kufareva, I., Katritch, V., Participants of, G. D., Stevens, R. C., and Abagyan, R. (2014). Advances in GPCR modeling evaluated by the GPCR Dock 2013 assessment: meeting new challenges. Structure 22, 1120-1139. doi: 10.1016/j.str.2014.06.012

Kufareva, I., Rueda, M., Katritch, V., Stevens, R. C., Abagyan, R., and Participants, G. D. (2011). Status of GPCR modeling and docking as reflected by community-wide GPCR Dock 2010 assessment. Structure 19, 1108-1126. doi: 10.1016/j.str.2011.05.012

Labadi, A., Grassi, E. S., Gellen, B., Kleinau, G., Biebermann, H., Ruzsa, B., et al. (2015). Loss-of-Function variants in a hungarian cohort reveal structural insights on TSH receptor maturation and signaling. J. Clin. Endocrinol. Metab. 100, E1039-E1045. doi: 10.1210/jc.2014-4511

Lagerstrom, M. C., and Schioth, H. B. (2008). Structural diversity of G proteincoupled receptors and significance for drug discovery. Nat. Rev. Drug Discov. 7 , 339-357. doi: $10.1038 / \mathrm{nrd} 2518$

Lai, P. C., and Crasto, C. J. (2012). Beyond modeling: all-atom olfactory receptor model simulations. Front. Genet. 3:61. doi: 10.3389/fgene.2012.00061

Lai, P. C., Guida, B., Shi, J., and Crasto, C. J. (2014). Preferential binding of an odor within olfactory receptors: a precursor to receptor activation. Chem. Senses 39, 107-123. doi: 10.1093/chemse/bjt060

Lai, P. C., Singer, M. S., and Crasto, C. J. (2005). Structural activation pathways from dynamic olfactory receptor-odorant interactions. Chem. Senses 30, 781-792. doi: 10.1093/chemse/bji070

Latorraca, N. R., Venkatakrishnan, A. J., and Dror, R. O. (2017). GPCR dynamics: structures in motion. Chem. Rev. 117, 139-155. doi: 10.1021 /acs.chemrev.6b00177

Launay, G., Sanz, G., Pajot-Augy, E., and Gibrat, J. F. (2012). Modeling of mammalian olfactory receptors and docking of odorants. Biophys. Rev. 4, 255-269. doi: 10.1007/s12551-012-0080-0

Lee, B., and Richards, F. (1971). The interpretation of protein structures: estimation of static accessibility, J. Mol. Biol. 55, 379-400. doi: 10.1016/0022-2836(71)90324-X

Lee, R. J., and Cohen, N. A. (2014). Bitter and sweet taste receptors in the respiratory epithelium in health and disease. J. Mol. Med. 92, 1235-1244. doi: 10.1007/s00109-014-1222-6

Lee, R. J., Xiong, G. X., Kofonow, J. M., Chen, B., Lysenko, A., Jiang, P. H., et al. (2012). T2R38 taste receptor polymorphisms underlie susceptibility to upper respiratory infection. J. Clin. Invest. 122, 4145-4159. doi: 10.1172/JCI64240

Leguebe, M., Nguyen, C., Capece, L., Hoang, Z., Giorgetti, A., and Carloni, P. (2012). Hybrid molecular mechanics/coarse-grained simulations for structural prediction of G-protein coupled receptor/ligand complexes. PLoS ONE 7:e47332. doi: 10.1371/journal.pone.0047332

Le Guilloux, V., Schmidtke, P., and Tuffery, P. (2009). Fpocket: an open source platform for ligand pocket detection. BMC Bioinformatics 10:168. doi: 10.1186/1471-2105-10-168

Lu, P., Zhang, C. H., Lifshitz, L. M., and ZhuGe, R. (2017). Extraoral bitter taste receptors in health and disease. J. Gen. Physiol. 149, 181-197. doi: 10.1085/jgp.201611637

Lund, T. C., Kobs, A. J., Kramer, A., Nyquist, M., Kuroki, M. T., Osborn, J., et al. (2013). Bone marrow stromal and vascular smooth muscle cells have chemosensory capacity via bitter taste receptor expression. PLOS ONE 8:e58945. doi: 10.1371/journal.pone.0058945

Lundstrom, K. (2009). An overview on GPCRs and drug discovery: structure-based drug design and structural biology on GPCRs. Methods Mol. Biol. 552, 51-66. doi: 10.1007/978-1-60327-317-6_4

Ma, X., Guan, L., Wu, W., Zhang, Y., Zheng, W., Gao, Y. T., et al. (2015). Whole-exome sequencing identifies OR2W3 mutation as a cause of autosomal dominant retinitis pigmentosa. Sci. Rep. 5:9236. doi: 10.1038/srep09236 
Malki, A., Fiedler, J., Fricke, K., Ballweg, I., Pfaffl, M. W., and Krautwurst, D. (2015). Class I odorant receptors, TAS1R and TAS2R taste receptors, are markers for subpopulations of circulating leukocytes. J. Leukoc. Biol. 97, 533-545. doi: 10.1189/jlb.2A0714-331RR

Malnic, B., Godfrey, P. A., and Buck, L. B. (2004). The human olfactory receptor gene family. Proc. Natl. Acad. Sci. 101, 2584-2589.

Manning, C. D., and Schütze, H. (1999). Foundations of Statistical Natural Language Processing. Cambridge, MA: MIT Press.

Manson, M. L., Safholm, J., Al-Ameri, M., Bergman, P., Orre, A. C., Sward, K., et al. (2014). Bitter taste receptor agonists mediate relaxation of human and rodent vascular smooth muscle. Eur. J. Pharmacol. 740, 302-311. doi: 10.1016/j.ejphar.2014.07.005

Marchiori, A., Capece, L., Giorgetti, A., Gasparini, P., Behrens, M., Carloni, P., et al. (2013). Coarse-grained/molecular mechanics of the TAS2R38 bitter taste receptor: experimentally-validated detailed structural prediction of agonist binding. PLoS ONE 8:e64675. doi: 10.1371/journal.pone.0064675

Matsunami, H., Montmayeur, J. P., and Buck, L. B. (2000). A family of candidate taste receptors in human and mouse. Nature 404, 601-604. doi: $10.1038 / 35007072$

Matthews, H. R., and Reisert, J. (2003). Calcium, the two-faced messenger of olfactory transduction and adaptation. Curr. Opin. Neurobiol. 13, 469-475. doi: 10.1016/S0959-4388(03)00097-7

Melo, F., Sanchez, R., and Sali, A. (2002). Statistical potentials for fold assessment. Protein Sci. 11, 430-448. doi: 10.1002/pro.110430

Meyerhof, W. (2005). Elucidation of mammalian bitter taste. Rev. Physiol. Biochem. Pharmacol. 154, 37-72. doi: 10.1007/s10254-005-0041-0

Meyerhof, W., Batram, C., Kuhn, C., Brockhoff, A., Chudoba, E., Bufe, B., et al. (2010). The molecular receptive ranges of human TAS2R bitter taste receptors. Chem. Senses 35, 157-170. doi: 10.1093/chemse/bjp092

Miao, Y., and McCammon, J. A. (2016). G-protein coupled receptors: advances in simulation and drug discovery. Curr. Opin. Struct. Biol. 41, 83-89. doi: 10.1016/j.sbi.2016.06.008

Michino, M., Abola, E., Participants, G. D., Brooks, C. L. III., Dixon, J. S., Moult, J., et al. (2009). Community-wide assessment of GPCR structure modelling and ligand docking: GPCR Dock 2008. Nat. Rev. Drug Discov. 8, 455-463. doi: $10.1038 / \mathrm{nrd} 2877$

Munk, C., Harpsoe, K., Hauser, A. S., Isberg, V., and Gloriam, D. E. (2016). Integrating structural and mutagenesis data to elucidate GPCR ligand binding. Curr. Opin. Pharmacol. 30, 51-58. doi: 10.1016/j.coph.2016.07.003

Musiani, F., Giorgetti, A., and Carloni, P. (2015). "Molecular Mechanics/Coarsegrain simulations as a structural prediction tool for GPCRs/ligand complexes," in In Silico Drug Discovery and Design: Theory, Methods, Challenges and Applications. (Boca Raton, FL: CRC Press), 337-352.

Musiani, F., Rossetti, G., Giorgetti, A., and Carloni, P. (2014). Chemosensorial Gproteins-coupled receptors: a perspective from computational methods. Protein Conformat. Dynam. 805, 441-457. doi: 10.1007/978-3-319-02970-2_18

Neri, M., Anselmi, C., Cascella, M., Maritan, A., and Carloni, P. (2005). Coarsegrained model of proteins incorporating atomistic detail of the active site. Phys. Rev. Lett. 95:218102. doi: 10.1103/PhysRevLett.95.218102

Neri, M., Baaden, M., Carnevale, V., Anselmi, C., Maritan, A., and Carloni, P. (2008). Microseconds dynamics simulations of the outer-membrane protease T. Biophys. J. 94, 71-78. doi: 10.1529/biophysj.107.116301

Neuhaus, E. M., Zhang, W., Gelis, L., Deng, Y., Noldus, J., and Hatt, H. (2009). Activation of an olfactory receptor inhibits proliferation of prostate cancer cells. J. Biol. Chem. 284, 16218-16225. doi: 10.1074/jbc.M109.012096

Noe, F., Polster, J., Geithe, C., Kotthoff, M., Schieberle, P., and Krautwurst, D. (2016). OR2M3: a highly specific and narrowly tuned human odorant receptor for the sensitive detection of onion key food odorant 3-mercapto2-methylpentan-1-ol. Chem. Senses 42, 195-210. doi: 10.1093/chemse/ bjw118

Nordstrom, K. J. V., Almen, M. S., Edstam, M. M., Fredriksson, R., and Schioth, H. B. (2011). Independent HHsearch, Needleman-Wunsch-Based, and Motif Analyses Reveal the Overall Hierarchy for Most of the G Protein-Coupled Receptor Families. Mol. Biol. Evol. 28, 2471-2480. doi: 10.1093/molbev/ msr061

Nygaard, R., Valentin-Hansen, L., Mokrosinski, J., Frimurer, T. M., and Schwartz, T. W. (2010). Conserved water-mediated hydrogen bond network between
TM-I, -II, -VI, and -VII in 7TM receptor activation. J. Biol. Chem. 285, 19625-19636. doi: 10.1074/jbc.M110.106021

Pardo, L., Deupi, X., Dolker, N., Lopez-Rodriguez, M. L., and Campillo, M. (2007). The role of internal water molecules in the structure and function of the rhodopsin family of $\mathrm{G}$ protein-coupled receptors. Chembiochem 8, 19-24. doi: 10.1002/cbic.200600429

Pei, J., Kim, B. H., Tang, M., and Grishin, N. V. (2007). PROMALS web server for accurate multiple protein sequence alignments. Nucleic Acids Res. 35, W649-W652. doi: 10.1093/nar/gkm227

Pettersen, E. F., Goddard, T. D., Huang, C. C., Couch, G. S., Greenblatt, D. M., Meng, E. C., et al. (2004). UCSF Chimera-a visualization system for exploratory research and analysis. J. Comput. Chem. 25, 1605-1612. doi: 10.1002/jcc.20084

Piccoli, S., Suku, E., Garonzi, M., and Giorgetti, A. (2013). Genome-wide membrane protein structure prediction. Curr. Genomics 14, 324-329. doi: 10.2174/13892029113149990009

Pluznick, J. L., Zou, D. J., Zhang, X., Yan, Q., Rodriguez-Gil, D. J., Eisner, C., et al. (2009). Functional expression of the olfactory signaling system in the kidney. Proc. Natl. Acad. Sci. U.S.A. 106, 2059-2064. doi: 10.1073/pnas.0812859106

Pronin, A. N., Tang, H., Connor, J., and Keung, W. (2004). Identification of ligands for two human bitter T2R receptors. Chem. Senses 29, 583-593. doi: 10.1093/chemse/bjh064

Pydi, S. P., Bhullar, R. P., and Chelikani, P. (2012). Constitutively active mutant gives novel insights into the mechanism of bitter taste receptor activation. J. Neurochem. 122, 537-544. doi: 10.1111/j.1471-4159.2012.07808.x

Pydi, S. P., Bhullar, R. P., and Chelikani, P. (2014a). Constitutive activity of bitter taste receptors (T2Rs). Adv. Pharmacol. 70, 303-326. doi: 10.1016/B978-0-12-417197-8.00010-9

Pydi, S. P., Jafurulla, M., Wai, L., Bhullar, R. P., Chelikani, P., and Chattopadhyay, A. (2016). Cholesterol modulates bitter taste receptor function. Biochim. Biophys. Acta 1858, 2081-2087. doi: 10.1016/j.bbamem.2016.06.005

Pydi, S. P., Singh, N., Upadhyaya, J., Bhullar, R. P., and Chelikani, P. (2014b). The third intracellular loop plays a critical role in bitter taste receptor activation. Biochim. Biophys. Acta 1838(1 Pt B), 231-236. doi: 10.1016/j.bbamem.2013.08.009

Pydi, S. P., Sobotkiewicz, T., Billakanti, R., Bhullar, R. P., Loewen, M. C., and Chelikani, P. (2014c). Amino acid derivatives as bitter taste receptor (T2R) blockers. J. Biol. Chem. 289, 25054-25066. doi: 10.1074/jbc.M114.576975

Raghavan, V., Bollmann, P., and Jung, G. S. (1989). A critical investigation of recall and precision as measures of retrieval system performance. ACM Trans. Inf. Syst. 7, 205-229. doi: 10.1145/65943.65945

Restrepo, D., Miyamoto, T., Bryant, B. P., and Teeter, J. H. (1990). Odor stimuli trigger influx of calcium into olfactory neurons of the channel catfish. Science 249, 1166-1168. doi: 10.1126/science. 2168580

Ring, A. M., Manglik, A., Kruse, A. C., Enos, M. D., Weis, W. I., Garcia, K. C., et al. (2013). Adrenaline-activated structure of the $\beta 2$-adrenoceptor stabilized by an engineered nanobody. Nature 502, 575-579. doi: 10.1038/nature12572

Robinett, K. S., Koziol-White, C. J., Akoluk, A., An, S. S., Panettieri, R. A., and Liggett, S. B. (2014). Bitter taste receptor function in asthmatic and nonasthmatic human airway smooth muscle cells. Am. J. Respir. Cell Mol. Biol. 50, 678-683. doi: 10.1165/rcmb.2013-0439RC

Rodriguez, M., Luo, W., Weng, J., Zeng, L., Yi, Z., Siwko, S., et al. (2014). PSGR promotes prostatic intraepithelial neoplasia and prostate cancer xenograft growth through NF- $\kappa$ B. Oncogenesis 3:e114. doi: 10.1038/oncsis.2014.29

Saito, T., and Rehmsmeier, M. (2015). The precision-recall plot is more informative than the ROC plot when evaluating binary classifiers on imbalanced datasets. PLoS ONE 10:e0118432. doi: 10.1371/journal.pone.0118432

Sakurai, T., Misaka, T., Ishiguro, M., Masuda, K., Sugawara, T., Ito, K., et al. (2010). Characterization of the beta-D-glucopyranoside binding site of the human bitter taste receptor hTAS2R16. J. Biol. Chem. 285, 28373-28378. doi: 10.1074/jbc.M110.144444

Salon, J. A., Lodowski, D. T., and Palczewski, K. (2011). The significance of G protein-coupled receptor crystallography for drug discovery. Pharmacol. Rev. 63, 901-937. doi: 10.1124/pr.110.003350

Sandal, M., Behrens, M., Brockhoff, A., Musiani, F., Giorgetti, A., Carloni, P., et al. (2015). Evidence for a transient additional ligand binding site in the TAS2R46 bitter taste receptor. J. Chem. Theory Comput. 11, 4439-4449. doi: 10.1021/acs.jctc.5b00472 
Sandal, M., Duy, T. P., Cona, M., Zung, H., Carloni, P., Musiani, F., et al. (2013). GOMoDo: a GPCRs online modeling and docking webserver. PLoS ONE 8:e74092. doi: 10.1371/journal.pone.0074092

Schioth, H. B., and Fredriksson, R. (2005). The GRAFS classification system of Gprotein coupled receptors in comparative perspective. Gen. Comp. Endocrinol. 142, 94-101. doi: 10.1016/j.ygcen.2004.12.018

Schlyer, S., and Horuk, R. (2006). I want a new drug: G-protein-coupled receptors in drug development. Drug Discov. Today 11, 481-493. doi: 10.1016/j.drudis.2006.04.008

Schmiedeberg, K., Shirokova, E., Weber, H. P., Schilling, B., Meyerhof, W., and Krautwurst, D. (2007). Structural determinants of odorant recognition by the human olfactory receptors OR1A1 and OR1A2. J. Struct. Biol. 159, 400-412. doi: 10.1016/j.jsb.2007.04.013

Schuttelkopf, A. W., and van Aalten, D. M. (2004). PRODRG: a tool for highthroughput crystallography of protein-ligand complexes. Acta Crystallogr. D Biol. Crystallogr. 60(Pt 8), 1355-1363. doi: 10.1107/S0907444904011679

Scott, W. R., Hünenberger, P. H., Tironi, I. G., Mark, A. E., Billeter, S. R., Fennen, J., et al. (1999). The GROMOS biomolecular simulation program package. J. Phys. Chem. A 103, 3596-3607. doi: 10.1021/jp984217f

Shaik, F. A., Singh, N., Arakawa, M., Duan, K., Bhullar, R. P., and Chelikani, P. (2016). Bitter taste receptors: Extraoral roles in pathophysiology. Int. J. Biochem. Cell Biol. 77(Pt B), 197-204. doi: 10.1016/j.biocel.2016.03.011

Shen, M. Y., and Sali, A. (2006). Statistical potential for assessment and prediction of protein structures. Protein Sci. 15, 2507-2524. doi: 10.1110/ps.062416606

Singh, N., Pydi, S. P., Upadhyaya, J., and Chelikani, P. (2011a). Structural basis of activation of bitter taste receptor T2R1 and comparison with Class A G-protein-coupled receptors (GPCRs). J. Biol. Chem. 286, 36032-36041. doi: 10.1074/jbc.M111.246983

Singh, N., Vrontakis, M., Parkinson, F., and Chelikani, P. (2011b). Functional bitter taste receptors are expressed in brain cells. Biochem. Biophys. Res. Commun. 406, 146-151. doi: 10.1016/j.bbrc.2011.02.016

Soding, J. (2005). Protein homology detection by HMM-HMM comparison. Bioinformatics 21, 951-960. doi: 10.1093/bioinformatics/bti125

Soding, J., Biegert, A., and Lupas, A. N. (2005). The HHpred interactive server for protein homology detection and structure prediction. Nucleic Acids Res. 33, W244-W248. doi: 10.1093/nar/gki408

Spehr, M., Gisselmann, G., Poplawski, A., Riffell, J. A., Wetzel, C. H., Zimmer, R. K., et al. (2003). Identification of a testicular odorant receptor mediating human sperm chemotaxis. Science 299, 2054-2058. doi: 10.1126/science.1080376

Spehr, M., Schwane, K., Riffell, J. A., Barbour, J., Zimmer, R. K., Neuhaus, E. M., et al. (2004). Particulate adenylate cyclase plays a key role in human sperm olfactory receptor-mediated chemotaxis. J. Biol. Chem. 279, 40194-40203. doi: 10.1074/jbc.M403913200

Spyrakis, F., BidonChanal, A., Barril, X., and Luque, F. J. (2011). Protein flexibility and ligand recognition: challenges for molecular modeling. Curr. Top. Med. Chem. 11, 192-210. doi: 10.2174/156802611794863571

Spyrakis, F., and Cavasotto, C. N. (2015). Open challenges in structure-based virtual screening: receptor modeling, target flexibility consideration and active site water molecules description. Arch. Biochem. Biophys. 583, 105-119. doi: 10.1016/j.abb.2015.08.002

Stary, A., Suwattanasophon, C., Wolschann, P., and Buchbauer, G. (2007). Differences in (-)citronellal binding to various odorant receptors. Biochem. Biophys. Res. Commun. 361, 941-945. doi: 10.1016/j.bbrc.2007.07.137

Sternini, C. (2007). Taste receptors in the gastrointestinal tract. IV. Functional implications of bitter taste receptors in gastrointestinal chemosensing. Am. J. Physiol. Gastrointest. Liver Physiol. 292, G457-G461. doi: 10.1152/ajpgi.00411.2006

Strange, P. G. (2008). Agonist binding, agonist affinity and agonist efficacy at G protein-coupled receptors. Br. J. Pharmacol. 153, 1353-1363. doi: 10.1038/sj.bjp.0707672

Strange, P. G. (2010). Use of the GTP $\gamma$ S ([ $\left.{ }^{35} \mathrm{~S}\right] \mathrm{GTP} \gamma \mathrm{S}$ and Eu-GTP $\left.\gamma \mathrm{S}\right)$ binding assay for analysis of ligand potency and efficacy at $G$ protein-coupled receptors. Br. J. Pharmacol. 161, 1238-1249. doi: 10.1111/j.1476-5381.2010. 00963.x

Suku, E., Fierro, F., Giorgetti, A., Alfonso-Prieto, M., and Carloni, P. (2017). Multiscale simulations of membrane proteins: the case of bitter taste receptors. J. Sci. Adv. Mat. Dev. 2, 15-21. doi: 10.1016/j.jsamd.2017.03.001

Takeda, S., Kadowaki, S., Haga, T., Takaesu, H., and Mitaku, S. (2002). Identification of $G$ protein-coupled receptor genes from the human genome sequence. FEBS Lett. 520, 97-101. doi: 10.1016/S0014-5793(02) 02775-8

Tautermann, C. S. (2014). GPCR structures in drug design, emerging opportunities with new structures. Bioorg. Med. Chem. Lett. 24, 4073-4079. doi: 10.1016/j.bmcl.2014.07.009

Tehan, B. G., Bortolato, A., Blaney, F. E., Weir, M. P., and Mason, J. S. (2014). Unifying family A GPCR theories of activation. Pharmacol. Ther. 143, 51-60. doi: 10.1016/j.pharmthera.2014.02.004

Thomas, T., McLean, K. C., McRobb, F. M., Manallack, D. T., Chalmers, D. K., and Yuriev, E. (2014). Homology modeling of human muscarinic acetylcholine receptors. J. Chem. Inf. Model. 54, 243-253. doi: 10.1021/ci400502u

Tikhonova, I. G., and Fourmy, D. (2010). The family of G protein-coupled receptors: an example of membrane proteins. Methods Mol. Biol. 654, 441-454. doi: $10.1007 / 978-1-60761-762-4 \_23$

Trott, O., and Olson, A. J. (2010). AutoDock Vina: improving the speed and accuracy of docking with a new scoring function, efficient optimization, and multithreading. J. Comput. Chem. 31, 455-461. doi: 10.1002/jcc.21334

Trzaskowski, B., Latek, D., Yuan, S., Ghoshdastider, U., Debinski, A., and Filipek, S. (2012). Action of molecular switches in GPCRs-theoretical and experimental studies. Curr. Med. Chem. 19, 1090-1109. doi: 10.2174/092986712799320556

Venkatakrishnan, A. J., Deupi, X., Lebon, G., Heydenreich, F. M., Flock, T., Miljus, T., et al. (2016). Diverse activation pathways in class A GPCRs converge near the G-protein-coupling region. Nature 536, 484-487. doi: 10.1038/nature 19107

Venkatakrishnan, A. J., Deupi, X., Lebon, G., Tate, C. G., Schertler, G. F., and Babu, M. M. (2013). Molecular signatures of G-protein-coupled receptors. Nature 494, 185-194. doi: 10.1038/nature11896

Wang, J., Weng, J., Cai, Y., Penland, R., Liu, M., and Ittmann, M. (2006). The prostate-specific G-protein coupled receptors PSGR and PSGR2 are prostate cancer biomarkers that are complementary to alpha-methylacyl-CoA racemase. Prostate 66, 847-857. doi: 10.1002/pros.20389

Webb, B., and Sali, A. (2016). Comparative protein structure modeling using MODELLER. Curr. Protoc. Protein Sci. 86, 29 1-2 9 37. doi: 10.1002/cpps.20

Wendell, S., Wang, X., Brown, M., Cooper, M. E., DeSensi, R. S., Weyant, R. J., et al. (2010). Taste genes associated with dental caries. J. Dent. Res. 89, 1198-1202. doi: $10.1177 / 0022034510381502$

Wijten, P., van Holten, T., Woo, L. L., Bleijerveld, O. B., Roest, M., Heck, A. J. et al. (2013). High precision platelet releasate definition by quantitative reversed protein profiling-brief report. Arterioscler. Thromb. Vasc. Biol. 33, 1635-1638. doi: 10.1161/ATVBAHA.113.301147

Williams, C., and Hill, S. J. (2009). GPCR signaling: understanding the pathway to successful drug discovery. Methods Mol. Biol. 552, 39-50. doi: 10.1007/978-1-60327-317-6_3

Yarmolinsky, D. A., Zuker, C. S., and Ryba, N. J. (2009). Common sense about taste: from mammals to insects. Cell 139, 234-244. doi: 10.1016/j.cell.2009.10.001

Young, J. M., Endicott, R. M., Parghi, S. S., Walker, M., Kidd, J. M., and Trask, B. J. (2008). Extensive copy-number variation of the human olfactory receptor gene family. Am. J. Hum. Genet. 83, 228-242. doi: 10.1016/j.ajhg.2008.07.005

Zhao, H., Ivic, L., Otaki, J. M., Hashimoto, M., Mikoshiba, K., and Firestein, S. (1998). Functional expression of a mammalian odorant receptor. Science 279, 237-242. doi: 10.1126/science.279.5348.237

Zhou, B., Irwanto, A., Guo, Y. M., Bei, J. X., Wu, Q., Chen, G., et al. (2012). Exome sequencing and digital PCR analyses reveal novel mutated genes related to the metastasis of pancreatic ductal adenocarcinoma. Cancer Biol. Ther. 13, 871-879. doi: 10.4161/cbt.20839

Zhuang, H., Chien, M. S., and Matsunami, H. (2009). Dynamic functional evolution of an odorant receptor for sex-steroid-derived odors in primates. Proc. Natl. Acad. Sci. U.S.A. 106, 21247-21251. doi: 10.1073/pnas.0808378106

Conflict of Interest Statement: The authors declare that the research was conducted in the absence of any commercial or financial relationships that could be construed as a potential conflict of interest.

Copyright (c) 2017 Fierro, Suku, Alfonso-Prieto, Giorgetti, Cichon and Carloni. This is an open-access article distributed under the terms of the Creative Commons Attribution License (CC BY). The use, distribution or reproduction in other forums is permitted, provided the original author(s) or licensor are credited and that the original publication in this journal is cited, in accordance with accepted academic practice. No use, distribution or reproduction is permitted which does not comply with these terms. 